Article

\title{
Challenges and Enablers in BIM-Enabled Digital Transformation in Mega Projects: The Istanbul New Airport Project Case Study
}

\author{
Ozan Koseoglu ${ }^{1}$, Basak Keskin ${ }^{2, *}$ and Beliz Ozorhon ${ }^{3}$ \\ 1 Digital Living Services, Istanbul Park Bulvari, Royal Park Residence G8 Block, Istanbul 34956, Turkey; \\ ozan.koseoglu@digitalliving.services \\ 2 Department of Civil and Environmental Engineering, Syracuse University, Syracuse, NY 13244, USA \\ 3 Department of Civil Engineering, Bogazici University, Istanbul 34342, Turkey; beliz.ozorhon@boun.edu.tr \\ * Correspondence: bkeskin@syr.edu
}

Received: 30 March 2019; Accepted: 2 May 2019; Published: 7 May 2019

\begin{abstract}
The Architecture Engineering and Construction (AEC) sector has been working on an increasing number of mega projects having large scale investments worldwide. The majority of these mega projects are infrastructure projects that are comparatively more difficult to manage in terms of yielding an expected return of investments while increasing quality and productivity. Today's construction technology landscape offers a wide variety of innovative digital solutions for optimizing the project constraints of scope, time, cost, quality, and resources. Despite being one of the least digitized sectors, the AEC sector is currently ripe for adopting innovative digital solutions. It is observed that Building Information Modeling (BIM) has been rapidly adopted to tackle the ever-evolving challenges of mega infrastructure projects. This study investigates the challenges and enablers of utilizing an end-to-end BIM strategy for digital transformation of mega project delivery processes through a mega airport project case study, in order to contribute a solid strategic understanding in BIM implementation for mega infrastructure projects. The case study is followed with two-phased semi-structured interviews. Based on the findings, major challenges are sustaining continuous monitoring and controlling in the project execution, engineering complexity and aligning stakeholders' BIM learning curves whereas strategic control mechanisms, incentivizing the virtual collaborative environment, and continuous digital delivery are major enablers.
\end{abstract}

Keywords: building information modeling (BIM); digital transformation; mega projects; construction innovation; challenges; enablers

\section{Introduction}

Rapid urbanization and population growth lead to a significant rise in the construction activity around the world [1]. The number of mega-projects increases significantly to meet the demand for new infrastructure. Mega projects can be defined as large scale investment projects that have extensive economic, social, and environmental effects [2,3]. However, the construction industry is struggling to keep up with satisfying the ever-evolving needs of today's society while optimizing the project quality, cost, time, and scope. The industry is challenged with the increasing complexities and scale of the mega projects while remaining highly competitive, externally influenced and susceptible to a high risk of failure $[4,5]$. Accordingly, similar to many other sectors, the AEC sector also needs to experience digital disruption to tackle with the emerging challenges to create value within the project delivery processes. One of today's key trends for a successful business strategy is "combine and conquer" [6], which implies innovative business models via the transformation of the core design and engineering systems around the digital. Similarly, Gartner [7] defines digital business transformation as the process 
of exploiting digital technologies and supporting capabilities for a robust new digital business model. Building Information Modeling (BIM) implementation being a collaborative process in which all project stakeholders are involved in virtually designing, coordinating, and operating the physical representation of the structure is considered the centerpiece of the construction industry's digital transformation [8,9]. As a result, BIM technologies and processes have been perceived as one of the most promising tools in the AEC industry, and are employed at an increasing rate [10,11]. The adoption of innovative BIM technologies and processes throughout the project management phases, starting from planning to execution, and the leveraging of the integration of right semantic and geometric project data via a single virtual platform, are essential for the needed digital transformation in the sector.

Compared to the building industry, the infrastructure industry has been slow to adopt and apply BIM [12]. There are different challenges associated with large-scale infrastructure projects, and the BIM technology itself is not enough to introduce digital transformation without a robust underlying digital strategy from start to end. Even though there are numerous case studies associated with BIM use in building projects, studies on uncovering the BIM utilization strategies and methods in mega size infrastructure projects have still been lacking. The primary objective of this study is to depict a clear picture of BIM implementation processes at both the technical and strategic levels during the design, engineering and construction phases to digitally transform the project delivery of mega size infrastructure projects. The study adopts qualitative methods, including a detailed case study on a mega size airport project Istanbul New Airport Project (INA), two-phased semi-structured interviews, a thematic analysis, and data triangulation as a validation method that uses two other airport project cases. Overall, this study expands the buildings-centered state of the art in the implementation of BIM by detailing out the digitized delivery of one of the world's biggest airport projects from both strategic and technical perspectives to provide a scalable know-how for major stakeholders in the infrastructure sector.

\section{Background}

This study provides a strategic understanding of how, through BIM implementation, an integrated digital project delivery transforms INA's core design and engineering, and the construction processes around the digital, by exploring the following key areas: (a) An overview of the airport design and construction, (b) digital transformation by BIM as a construction innovation, and (c) BIM for the infrastructure. It is targeted to convey (a) the physical design and engineering complexity that is managed collaboratively in the 3D BIM environment, via (b) trends and progress in digitization, and how they are aligned with the way BIM innovates the construction industry, via (c) an overview of the progress and trends in BIM implementation for the infrastructure.

\subsection{An Overview of Airport Design and Construction}

Airports are highly complex and fragmented systems in terms of incorporating the design, construction and operation of a varying mix of infrastructure systems including terminals, piers, runways, taxiways, aprons, car parks, railways, roads, cargo areas, encapsulating many different types of construction. Airports are asset-intensive business systems that need to be designed and constructed in a way that meets the operational requirements of a successful asset, and of business management [13]. In essence, the issues regarding airport design and construction processes, as well as their management, can be projected on other types of infrastructure systems.

Airports can be divided into two regions: landside, which includes facilities associated with how passengers arrive and depart, and how they navigate the terminal building, and airside, which describes the movement of the airplanes and airport surface [14]. Airport design has evolved over time. After World War 2, airport design became more refined as supply and demand for air transport infrastructure increased significantly [15]. Starting from a decentralization trend that includes the use of piers, fixed linked bridges and jet bridge systems, the generics of airport design have transformed substantially. Increasing and changing demands and approaches to airport design and constriction have shaped today's modern airports [15]. As digital transformation changes the way the industries 
operate and as it triggers urbanization; the role, scale and meaning of urban airports worldwide have also changed as a result of this corporate and economic transformation [16]. Modern airports, which are also called 'airport cities', do not just offer terminal and runways operations, but also carparks, logistics, lounges, malls, hotels, retail areas, railway stations, and conference halls as well [13]. Hence, the wider metropolitan perspective of the modern airports increases the complexity in the land use and infrastructure [16], as well as the design and construction of the airports.

At the outset of the 21st century, people's needs and requirements are hyper-evolving, and there are many issues to be considered for complex system developments such as airports. For example, capacity, aircraft \& airport compatibility, sustainability and technology aspects can be listed as the key concerns in airport design [17]. Runways, taxiways and taxilanes, aprons, cargo ways, airport pavements, airport lighting, marking, signage, airport drainage, airport terminal areas including piers, car parks, airports security areas, maintenance, repair, and overhaul facilities, airport traffic controller (ATC) towers, airport people movers (APM), baggage handling systems (BHS) tunnels, underground infrastructure networks, can be considered as the major components of a commercial airport design [17].

Similar to other infrastructure systems, airports hold an extensive cultural and socio-economic value, and hub airports are usually signatory projects having a certain architectural attractiveness. Single roof canopies, an abundance of steel structures, green roofs, articulated facades, glazed openings, skylight apertures, pools, passive systems, and three dimensional representations can be listed as some of the preferred architectural features [15].

\subsection{Digital Transformation by Building Information Modeling as a Construction Innovation}

The dynamic competitive landscape of the AEC sector requires more innovative and digitally transformative solutions that require certain advancements in the information technology (IT) of the construction. As modern buildings and facilities get more complex in terms of the physical infrastructure, requiring a simultaneous coordination and approval of the design [18], a more ubiquitous access to information is needed. IT-driven competition started during the 1960s and 1970s via the automation of individual activities in the value chain, such as computer-aided design and manufacturing resources planning [19]. Moore [20] explains the evolutionary stages of the business ecosystem for advancements in IT in the 1970s, and how important continuous innovation is for maintaining the competitive edge. Heppelmann \& Porter [21] state that there are three waves of IT-driven competition, and we are now under the effect of the third wave that enables a dramatic increase in data capturing, analysis and productivity. The digital transformation era comes with the third wave, and revolutionizes the industries. Thus, the term Industry 4.0 has become popular worldwide as it triggers attention to the emerging technologies such as big data analytics, autonomous robots, cyber physical infrastructures, simulation, horizontal and vertical integration, cloud systems, augmented reality, and additive manufacturing [22].

BIM can be associated with the use of information and communication technology (ICT) in the construction sector for streamlining the project phases to increase productivity and efficiency. As ICT evolves in time, BIM technologies and processes also advance significantly, for over 40 years, conforming to the increase in complexity, needs, and requirements of today's AEC and infrastructure sector [23]. Accordingly, BIM has become widely accepted as one of the most revolutionary innovations in the global AEC industry, even though the exact origin of BIM is still open to discussion [24]. BIM is one of the key Industry 4.0. technologies that is considered the central technology for the digitization in construction, as simulation and modeling is stated as one of the conceptual clusters of Industry 4.0. [25]. BIM allows the sector to exploit the majority of the aforementioned emerging technologies, such as a cyber physical infrastructure, horizontal and vertical integration, cloud systems, and augmented reality. BIM, as a digital innovation, focuses on both the digital representation of information on the physical structure, and collaboration and project management [26], so that BIM can be considered an integral part of the construction innovation.

Even though the construction industry is criticized for being the slowest in adopting digital innovation despite being one of the largest industries generating a tenth of the planet's total gross 
domestic product (GDP) [27]; BIM unleashes a significant unbounded innovation potential for the industry at the inter-organizational level [28].

BIM applications continue to be adopted as a standard practice in the AEC industry at an increasing rate. The National Institute of Building Sciences building SMART alliance (2007) describes BIM as "a digital representation of physical and functional characteristics of a facility. As such, it serves as a shared knowledge resource for information about a facility forming a reliable basis for decisions during its lifecycle from inception onward." BIM allows the management and access of big data encompassing physical and operational data of the building structure. BIM implementation leads to numerous activities associated with design, engineering, project management and delivery; and all aspects of BIM can affect the asset and facility management phase [29]. BIM offers a holistic approach to construction management by integrating, visualizing, storing, updating, and managing all of the necessary project data in a digital environment, as well as their re-use by responsible parties any time during a construction project's life cycle. Thus, it introduces a collaborative interdisciplinary team experience to seamlessly manage the whole project life cycle in a highly fragmented industry setting.

Furthermore, BIM implementation as a technology innovation can be explored and analyzed from a high-level theoretical perspective of innovation diffusion. There have been many studies, using both theoretical and empirical approaches, to understand the diffusion of innovation in the building sector, and most of the innovation diffusions discussed in those studies are technological innovations [30]. Suggested models, frameworks, and approaches try to investigate the key parameters and metrics affecting innovation diffusion within different contexts of the construction sector. Some of them use the process view to explain the technology innovation adoption. Since BIM is both a process and product innovation, the way BIM successfully transforms the project is explained through a strong relation with its influence of connectivity and centralization on the inter-organizational level affecting the information supply chain $[26,28,30]$.

\subsection{BIM for Infrastructure}

Adopting a digital innovative model for the project delivery of an infrastructure project to produce sustainable design features is important. This notion becomes subtler as the size and complexity of the project increase. Accordingly, market reports mention that there has been a dramatic increase in BIM implementation in the transportation infrastructure, such that the organizations' use of BIM on more than half of their projects has been tripled between 2015 and 2019 [31]. This also shows that BIM has been increasingly employed as one of the most promising digital tools because it brings key benefits at the project and business levels in terms of cost, time, resources, and quality [32,33]. Furthermore, $62 \%$ of the firms doing aviation projects have a higher level of BIM implementation in the majority of their projects compared to the ones having roads, bridges, rail/mass transit or tunnel projects in their portfolios [31]. During the design and engineering, and the construction phases of a mega scale airport project, five main processes of design management, information management, quality control and assurance, resource management and performance management are addressed strategically through BIM implementation tools and processes [34]. For a modern airport project, as optimizing design and engineering decisions and accelerating the on-site progress can be achievable via the coordination and communication of all design/engineering disciplines on a virtual BIM platform, introducing lean synergies for the airport design and construction is also essential [34,35]. The use of BIM technologies and processes as a digital innovative model for airport design/engineering and construction phases provides significant budget and time improvements as lean efficiency gains [35]. Hence, eliminating waste via the creation of lean synergies is one of the focus areas for key airport design issues on sustainability and the use of technology.

\section{Methodology}

This research adopts a qualitative methodology, in which an explanatory case-study approach is followed by semi-structured interviews for data collection. The case study is a research strategy, trying 
to answer the how and why questions by focusing on contemporary events [36]. There are four quality measures, which are the constructing validity, internal validity, the causal relationships between the variables and results, the external validity, and the reliability for a case study's in-depth analysis [36]. Accordingly, we aim to make conceptual generalizations from the local context of the case study to other settings via the systematic collection of data from interviews, observations and documentation reviews [37]. A typical or average case is not often the richest in information, so the INA case is selected strategically and detailed out to increase the generalizability of the study [38]. Furthermore, since a semi-structured interview method has been proven to be both versatile and flexible, it is chosen as a rigorous data collection method for the study [39]. The actual interview questions are shared in Section 3.2. for other researchers to test and develop the analysis of a similar case.

As qualitative analysis renders the complexity of the study objective [40], one of the objectives is to develop generalizations regarding BIM implementation strategies used for realizing a digital transformation in mega-size infrastructure projects' delivery. According to Scapens [41], main steps in a case study are as follows: preparation; collecting evidence; assessing evidence; identifying and explaining patterns; and report writing. In this study, a similar approach is adopted. To assess the collected data in a systematic manner, and to delineate patterns, a framework for the analysis of the construction innovation process at the project level [42] is adopted. The framework involves interacting components of innovation, where the rate of innovation is influenced by challenges and enablers that enact negative and positive factors respectively. Accordingly, enablers and challenges are investigated to better understand how the BIM is implemented as a digital innovation in a mega airport project context. The challenges are the primary factors that inhibit innovation, such as an unsupportive organizational culture, lack of financial resources, unwillingness to change, financial risks, temporary nature of projects, and lack of collaboration among project partners, whereas enablers are the major tools/strategies employed to overcome challenges, such as collaborative partnering, a supportive work environment, leadership, commitment, knowledge management practices, reward schemes, and innovation policy [42].

To support the identified patterns, data triangulation is selected as a method. It also helps to establish the validity of the interpretations by examining comparable BIM journeys at Heathrow International Airport and Denver International Airport through the available literature, as well as relevant publicized project documents.

\subsection{The Istanbul New Airport (INA) Project Case}

Istanbul New Airport (INA) is an international airport which has been under construction since 2015 in the Arnavutkoy district on the European side of Istanbul, Turkey. INA targets to be the largest airport in the world with 3 terminals, 6 runways, and an annual capacity of 200 million passengers. In the INA Project, it is planned to have multiple terminals with multiple concourses that can be connected through walkways, sky-bridges, or tunnels. The project has four phases, and its first phase encompasses a single terminal (Terminal 1) which has a total area of approximately $900,000 \mathrm{~m}^{2}$. There are also pier finger terminals incorporated in the design of the terminal. There are 5 piers in total offering a total area of approximately $320,000 \mathrm{~m}^{2}$. Additionally, the INA project includes a multi-storey car park design with a total approximate area of $700,000 \mathrm{~m}^{2}$.

The INA project is a fast track, mega scale project delivered by the build-operate-transfer (BOT) method. The aforementioned targeted scales and capacities indicate the significant complexity and challenges which were intensified with the project timeline constraints so that the first phase of the project was started in 2015, and completed in the second half of 2018.

The INA BIM Master Model encompasses all the major structures residing on the airside and landside regions of the airport. The digital design/engineering details of the project are elaborated by providing the mechanical, electrical, and plumbing (MEP), as well as the infrastructure systems and sub-systems of the building and civil airport structures coordinated and/or present in the BIM environment (See Table 1). 
Table 1. Major modelled MEP and infrastructure systems according to their locations.

\begin{tabular}{|c|c|c|c|c|}
\hline \multirow{2}{*}{$\begin{array}{l}\text { The INA Project } \\
\text { Design/Engineering Systems }\end{array}$} & \multicolumn{4}{|c|}{ Airport Region/Structure } \\
\hline & Terminal Building & $\begin{array}{c}\text { Piers, ATC, Car Park, } \\
\text { Utility Center }\end{array}$ & Runways & Sitewide $^{1}$ \\
\hline MEP Systems & $\begin{array}{ll}\text { - } & \text { HVAC Ducting } \\
\text { - } & \text { HVAC Piping } \\
\text { - } & \text { Plumbing } \\
\text { - } & \text { Fire Protection } \\
\text { - } & \text { Electrical System (Cable } \\
& \text { trays, ducts) } \\
\text { - } & \text { Baggage Handlings System } \\
& \text { (BHS) including conveyors, BHS } \\
& \text { steel, cable trays and ladders) }\end{array}$ & $\begin{array}{ll}- & \text { HVAC Ducting } \\
- & \text { HVAC Piping } \\
\text { - } & \text { Plumbing } \\
\text { - } & \text { Fire Protection } \\
- & \text { Electrical System } \\
& \text { (Cable trays, ducts) }\end{array}$ & N/A & N/A \\
\hline Infrastructure Systems & & & $\begin{array}{l}\text { - Airside Drainage } \\
\text { including open channels, } \\
\text { culverts, filter drains, slot } \\
\text { drains, manholes, } \\
\text { and pipes } \\
\text { Aeronautical Ground } \\
\text { Lighting (AGL) Main } \\
\text { Infrastructure including } \\
\text { galleries, primary } \\
\text { ductbanks, manholes }\end{array}$ & $\begin{array}{ll}\text { - } & \text { Underground Networks } \\
\text { - } & \text { Fuel Hydrant } \\
\text { - } & \text { Fire Hydrant } \\
\text { - } & \text { Storm Water } \\
\text { - } & \text { Potable Supply } \\
\text { - } & \text { Grey Water } \\
\text { - } & \text { Natural Gas } \\
\text { - } & \text { Irrigation Line } \\
\text { - } & \text { Waste Water }\end{array}$ \\
\hline Other & & & - $\quad$ Surface Models & \\
\hline
\end{tabular}

${ }^{1}$ Sitewide is a project-specific classification used in the model zoning in the INA Project, representing the region between the landside and airside of the airport. 
The given systems in Table 1 are all modelled and coordinaetd in the BIM platform, and then delivered to the site through BIM cloud services for construction.

\subsection{Semi-Structured Interviews}

Two-phased semi-structured interviews were conducted with client-representative BIM team members of INA for the data collection. The INA BIM Team is composed of the BIM Director, BIM Manager, and BIM Engineers, and their answers reflect the owner perspective for the BIM implementation in a mega scale airport project. Two sets of semi-structured interview questions are prepared to have insights on the technical and strategic levels, separately. By differentiating those two levels, we target the exploration of technical BIM engineering details of the project execution through technical level semi-structured interviews with BIM Engineers and the BIM Manager; and executive BIM management insights from the strategic level semi-structured interview with the BIM Director-Chief Technical Officer (CTO). The results are provided by compiling and consolidating the data taken from each interview set.

To fulfill the objectives of the study, an adequate sample size is determined in view of the qualitative data saturation in the interviews. To systematically assess the saturation level, an information power model [43] is used as guidance. Accordingly, a single case analysis with a dense specificity, strong dialogues, and a narrow aim enables higher information power leading to the adequateness of a smaller sample size. This study focuses on the INA case, which focuses on exploring a niche research area BIM implementation for mega projects and includes co-located and closely working client representative interviewees either experiencing start-to-end BIM processes or overseeing them at an executive level. The number of participants for the first set of the interview is 8, corresponding to 1 BIM Manager and 7 BIM Engineers. In total, the sample size of the compiled semi-structured interviews is 9 . All of the interviewees are part of the INA BIM Management Team, and the they are all responsible for delivering the project by facilitating the communication between all project parties by providing and maintaining the coordinated BIM models. The roles and responsibilities of the interviewees are given in Table 2 . The question sets, which were prepared in view of the interviewees' roles and responsibilities, for each phase of the interview, are provided in Tables 3 and 4, respectively.

Table 2. Interviewees' roles and responsibilities [44].

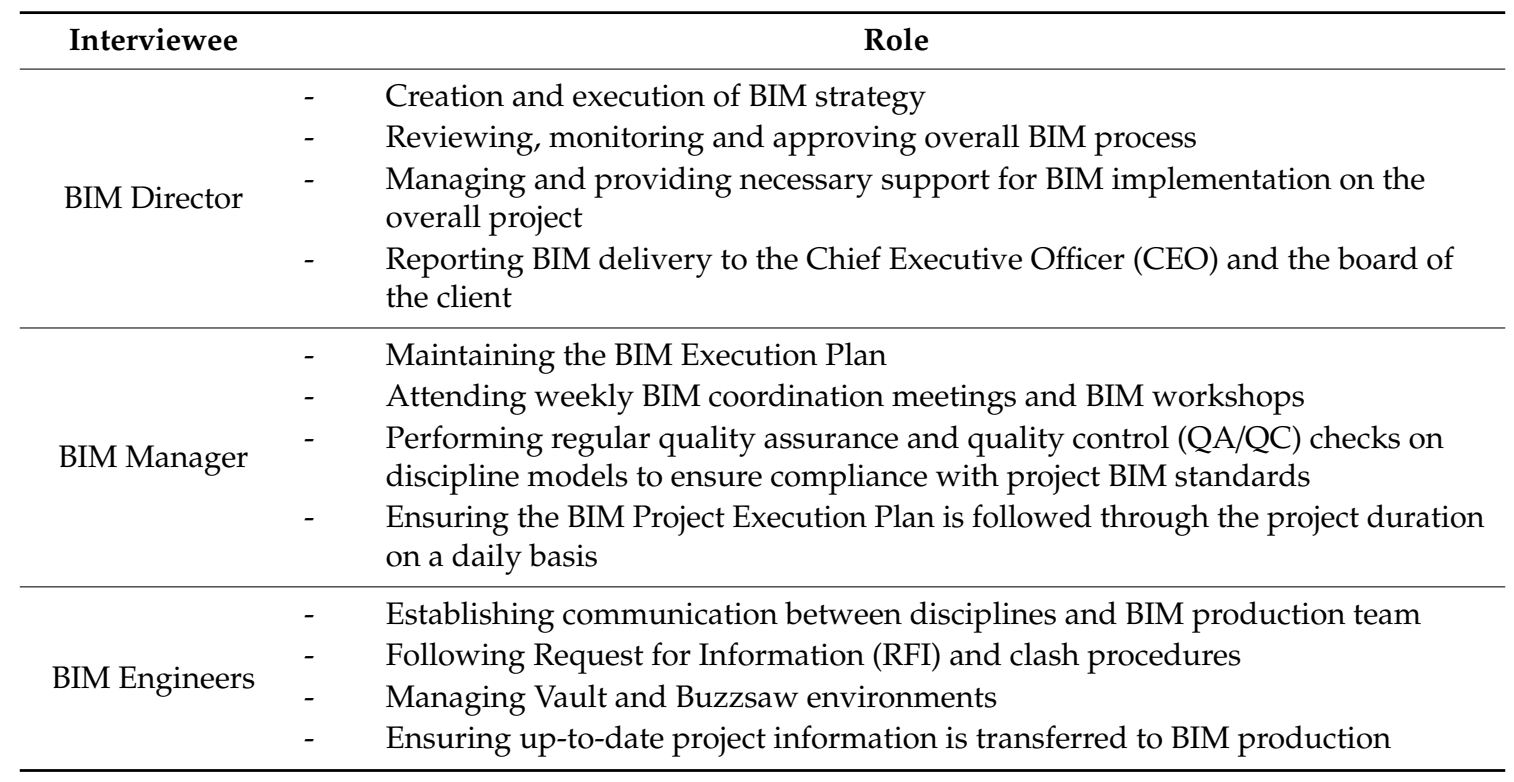


Table 3. The first set of interview questions.

\begin{tabular}{c} 
The First Set of Interview Questions \\
\hline Could you tell us about the airport project scope? \\
What are the key performance indicators? \\
\hline Could you tell us about the development of the BIM Plan from the conceptual stage? \\
\hline Could you tell us about how BIM is applied at the INA Project? \\
\hline How will BIM be used over the lifecycle of the airport?
\end{tabular}

Table 4. The second set of interview questions.

\begin{tabular}{c} 
The Second Set of Interview Questions \\
Could you tell us about the airport project scope? \\
Could you tell us about your role in BIM execution at the INA Project? \\
Could you tell us about how BIM is applied at the INA Project? \\
What are the key performance indicators? \\
\hline Could you tell us what are the key principles you use to customize the airport BIM implementation at the \\
INA Project? \\
\hline Could you tell us about the development of the BIM Strategy from the conceptual stage? \\
\hline How will BIM be used over the lifecycle of the airport, and what could be the potential results in the case of not \\
achieving BIM for operations?
\end{tabular}

\subsection{Construction Innovation Framework Approach: Enablers and Challenges in BIM Implementation}

This section focuses on giving a comprehensive background on the approach that identifies the enablers and challenges in the BIM implementation, followed in the study while conducting a qualitative analysis of the case study. The main enablers and challenges are identified specific to the BIM implementation based on an extensive literature review. The challenges are a lack of financial resources, lack of clear benefits, unsupportive organizational culture, lack of experienced BIM professionals, lack of awareness, lack of governmental support, and level of project complexity; whereas the enablers are a collaborative working environment, advanced project monitoring and control system, BIM tools, BIM Policy, BIM open standards, and organizational structure. The explanations and relevant sources for those identified factors can be found in Tables 5 and 6 respectively.

Table 5. Challenges of the BIM implementation. [44].

\begin{tabular}{|c|c|c|}
\hline Challenge & Description & Source \\
\hline $\begin{array}{l}\text { Lack of financial } \\
\text { resources }\end{array}$ & $\begin{array}{l}\text { BIM utilization requires a significant initial investment due to high costs } \\
\text { of sophisticated digital tools (e.g., BIM software, mobile tablets, etc.), } \\
\text { and education/training }\end{array}$ & {$[18,30]$} \\
\hline Lack of clear benefits & $\begin{array}{l}\text { It is hard to confirm that the realized benefits outweigh the costs of the } \\
\text { BIM implementation }\end{array}$ & {$[31,45,46]$} \\
\hline $\begin{array}{l}\text { Unsupportive } \\
\text { organizational } \\
\text { culture }\end{array}$ & $\begin{array}{l}\text { BIM implementation requires a change in technology and business } \\
\text { process which may not be easily aligned with an organization's culture } \\
\text { and capabilities based on the competencies of employees and } \\
\text { technological assets }\end{array}$ & {$[28,47,48]$} \\
\hline
\end{tabular}


Table 5. Cont.

\begin{tabular}{ccc}
\hline Challenge & Description & Source \\
\hline $\begin{array}{c}\text { Lack of experienced } \\
\text { BIM professionals }\end{array}$ & $\begin{array}{c}\text { Developing countries in particular struggle with a socio-economic and } \\
\text { technological environment that hinders research and development so } \\
\text { that the increase in qualified personnel }\end{array}$ & {$[48-50]$} \\
\hline Lack of awareness & $\begin{array}{c}\text { Organizational awareness of the importance of the BIM implementation } \\
\text { is a critical factor for the BIM maturity level which refers to the quality, } \\
\text { repeatability and degree of excellence within the BIM capability }\end{array}$ & {$[51,52]$} \\
\hline $\begin{array}{c}\text { Lack of governmental } \\
\text { support }\end{array}$ & $\begin{array}{c}\text { There should be a BIM policy dictating a systematic and standardized } \\
\text { approach for the BIM implementation together with incentives }\end{array}$ & {$[51,53]$} \\
\hline $\begin{array}{c}\text { Level of project } \\
\text { complexity }\end{array}$ & $\begin{array}{c}\text { BIM users having insufficient experience might have significant } \\
\text { coordination problems while trying to implement BIM for highly } \\
\text { complex projects, and the greater the number of stakeholders, the } \\
\text { harder it gets to control the BIM use of each party. }\end{array}$ & {$[45,50,54]$} \\
\hline
\end{tabular}

Table 6. Enablers of the BIM implementation.

\begin{tabular}{ccc}
\hline Enabler & Description & Source \\
\hline $\begin{array}{c}\text { Collaborative } \\
\text { working environment }\end{array}$ & $\begin{array}{c}\text { BIM integrates all stakeholders in a virtual environment to } \\
\text { facilitate a collaborative working environment [44] }\end{array}$ & {$[12,24,55-59]$} \\
\hline $\begin{array}{c}\text { Advanced project } \\
\text { monitoring and } \\
\text { control system }\end{array}$ & $\begin{array}{c}\text { BIM controls the subcontractors and eliminates any unforeseen } \\
\text { cost over-runs while reducing waste on site, such as cost, time } \\
\text { and quality [44] }\end{array}$ & {$[34,35,57,59,60]$} \\
\hline BIM tools & Advanced digital tools provide rapid access to real-time project \\
data for different phases of the project & {$[12,18,23,61]$} \\
BIM policy & $\begin{array}{c}\text { Companies' BIM strategies (e.g., BIM execution plans and } \\
\text { roadmap workflows) and government mandates lead to an } \\
\text { increase in project individuals' awareness toward BIM use [44] }\end{array}$ & {$[26,32,55,61-63]$} \\
\hline $\begin{array}{c}\text { Open standards } \\
\text { for BIM }\end{array}$ & $\begin{array}{c}\text { Use of Object-based data models (e.g., IFC) improve the data } \\
\text { exchange between different software, and target } \\
\text { interoperability issues }\end{array}$ & {$[32,56]$} \\
\hline $\begin{array}{c}\text { Organizational } \\
\text { structure }\end{array}$ & $\begin{array}{r}\text { Optimal inter-organizational and/or intra-organizational } \\
\text { hierarchy that facilitates the adoption of BIM at the project } \\
\text { and/or organizational level }\end{array}$ & {$[64-66]$} \\
\hline
\end{tabular}

\subsection{Semi-Structured Interview Data Analysis Approach}

A thematic analysis is conducted to identify patterns and themes in the collected qualitative data by coding the inputs recorded in the semi-structured interview sessions. The thematic analysis begins at the stage of the data collection and data entry, and continues throughout the coding and interpreting of the data [67]. The themes are determined as technical level challenges, strategic level challenges, technical level enablers, and strategic level enablers. The themes are coded by the data aggregated from the first-phased and second-phased interview questions. A qualitative data analysis software package, NVivo, is used to perform the coding process shown in Figure 1. As can be seen in Tables 3 and 4, there are several common questions provided in both interview question sets to observe saturation regarding certain challenges and enablers perceived by the interviewees with different roles. These saturation points are related to the nodes of strategic perspective. 


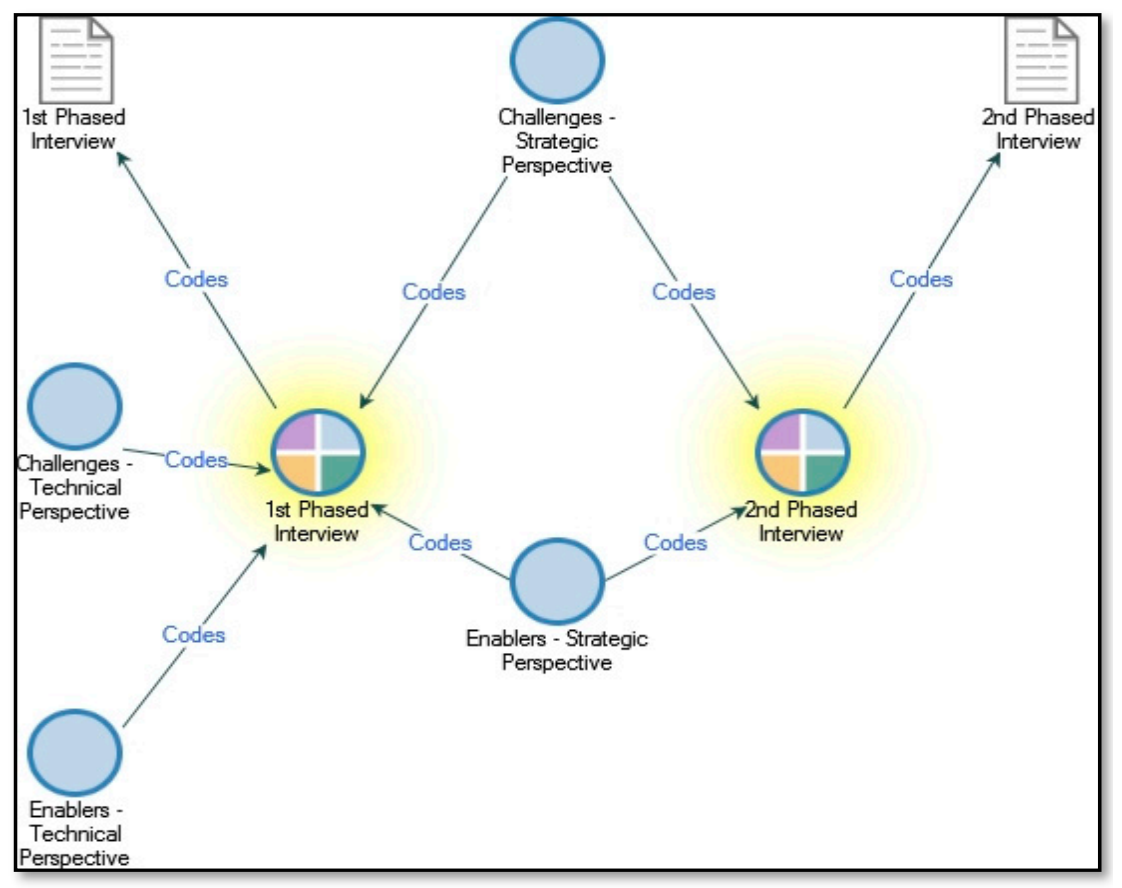

Figure 1. Semi-structured interview data coding scheme.

\subsection{Data Triangulation}

Data source triangulation involves the collection of data from different types of people, including individuals, groups, families, and communities, to gain multiple perspectives and the validation of data [68]. In terms of both design and construction, and the use of BIM as a digital innovation, London Heathrow International Airport (LHR) and Denver International Airport (DEN) have similar features and trends with the INA Project. Residing on different geographies and possessing a similar significance, complexity, and scale strengthen the data triangulation. For instance, similar to the INA case, Heathrow T5 was the largest construction project within its own region, the UK, at the time [45]. The project characteristics of LHR and DEN are provided in Table 7.

Table 7. General information on the selected projects for data triangulation.

\begin{tabular}{ccc}
\hline General Project Information & London Heathrow Airport & $\begin{array}{c}\text { Denver } \\
\text { International Airport }\end{array}$ \\
\hline Project Name & Heathrow Fifth Terminal (T5) Project & Hotel and Transit Centre Program \\
\hline Project Size & $465,000 \mathrm{~m}^{2}[15]$ & $758,000 \mathrm{ft}^{2}[69]$ \\
\hline Budget & $£ 4.2$ billon [45] & $\$ 719$ million [69] \\
\hline Project Timeline & 7 years (2001-2008) [45] & 5 years (2011-2016) \\
\hline Project Type & Expansion & Expansion \\
\hline Project Delivery Method & Multiple projects with different methods & CM/GC ${ }^{1}[69]$ \\
\hline \multicolumn{2}{c}{${ }^{1}$ Construction Manager/General Contractor which is also called CM-at Risk (CMR). }
\end{tabular}

The general information on the cases of DEN and LHR, together with the extent of their BIM use, can also be used for making projections to provide a clearer picture of the scale of the complexity and the transformation present in the INA case. Both cases are investigated from the client's perspective, as in the INA case. 


\section{Case Analysis}

The INA Project case is explored by assessing the qualitative data gathered regarding the BIM implementation processes, with respect to the construction innovation framework components of challenges and enablers. Both challenges and enablers are demonstrated from technical and strategic level perspectives.

\subsection{Challenges}

A first set of semi-structured interviews conducted with BIM Engineers and the BIM Manager revealed the challenges the project faced from a technical perspective. The interpretations of the data collected from the second set, a semi-structured interview with the project's CTO, demonstrate a strategic level perspective used to implement a start-to-end BIM implementation strategy. In essence, the findings are presented accordingly by being categorized as either "technical level perspective" or "strategic level perspective". According to the findings, the analyzed challenges can be associated with the project complexity, lack of experienced BIM professionals, lack of awareness, and unsupportive organizational culture.

\section{Technical Perspective}

The project's competitive phased nature brings challenging operational goals within the means of engineering management. Solving the concurrently evolving design/engineering and construction issues while keeping track of the project baseline schedule on-site, together with ensuring safety, is what represents the KPIs from a technical perspective. Thus, one major categorization of challenges is virtual design/engineering problems. There are specific disciplines that have been reported that are comparatively hard to manage within the BIM environment due to their type of deliverables, high coordination interdependencies, and scales. Accordingly, the clash resolution process, related to the coordination between MEP systems and special airport systems (SAS), has become one of the major challenges both in the design and construction phase, and concerns a wide variety of project individuals. Managing the flow of request for information (RFI) and incorporating the solutions, which have been generated from different discipline perspectives, represent a major engineering management challenge.

An airport project, due to its nature, requires very different and complex types of mechanical systems that need large areas to be placed and to be activated together. Figures 2 and 3 are viewpoints, which focus on the terminal and pier building regions respectively, are taken from the merged model of the airport landside and airside MEP and the infrastructure cross-coordinated model elements (listed in Table 1). They depict the significant challenge of the project's engineering complexity; the clusters of various types of MEP elements (e.g., HVAC ducting, plumbing pipes, fire sprinklers, electrical and IT cable trays, and heating and cooling pipes) shown at all of the levels of the terminal building and pier building areas, and the underground network infrastructure (e.g., electrical duct bank, drainage, and waste water) distributed over the sitewide region, require iterative coordination and modeling for the on-site shop drawing production and manufacturing. Furthermore, because of dramatic space constraints, the virtual coordination became significantly challenging, and continuous input from the INA site engineers was required before synchronizing the coordinated model on the cloud and sharing it with all of the project parties.

BHS design coordination and placement on the site were significant engineering challenges in the INA Project due to the requisite accuracy and the length $(42 \mathrm{~km})$ of the baggage routing. Initial coordination decisions regarding the placement of the MEP systems, including the HVAC ducting, piping, and the electrical and IT cable trays within the architectural and structural envelope, were made according to the BHS systems' placement. Figure 4 provides a closer look of the BHS systems in the terminal building area, and articulates the cross-coordination complexity within a highly congested area. The BHS systems, and the MEP systems in the surrounding areas, are highlighted in Figure 4. 
One of the struggling processes was reported as the coordination at knuckle points where terminal and pier buildings are connected. These points are some of the most congested areas in terms of MEP-IT elements. Their clash-free placement, considering the architectural and structural transition of spaces, became significantly challenging both on-site and at the office.

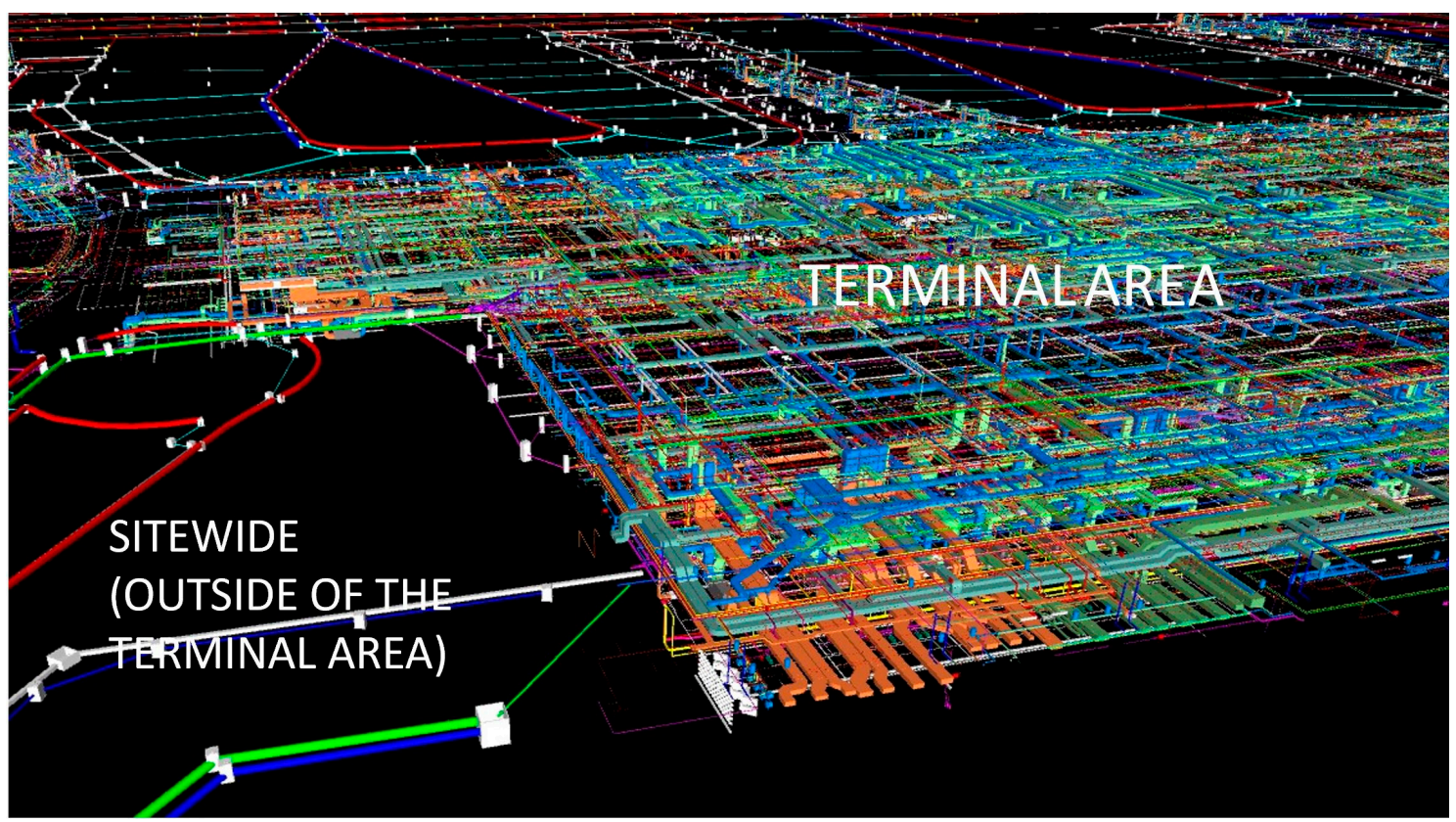

Figure 2. Viewpoint of the Merged MEP-Infrastructure INA BIM Model. Blue \& Green \& Orange: HVAC Ducts, Yellow \& Purple: Waste water discharge line, Red (inside the terminal area): Fire protection, Red (outside the terminal area): Underground network line composed of pipes, manholes, and slot drains, Green (outside the terminal area): Landside drainage.

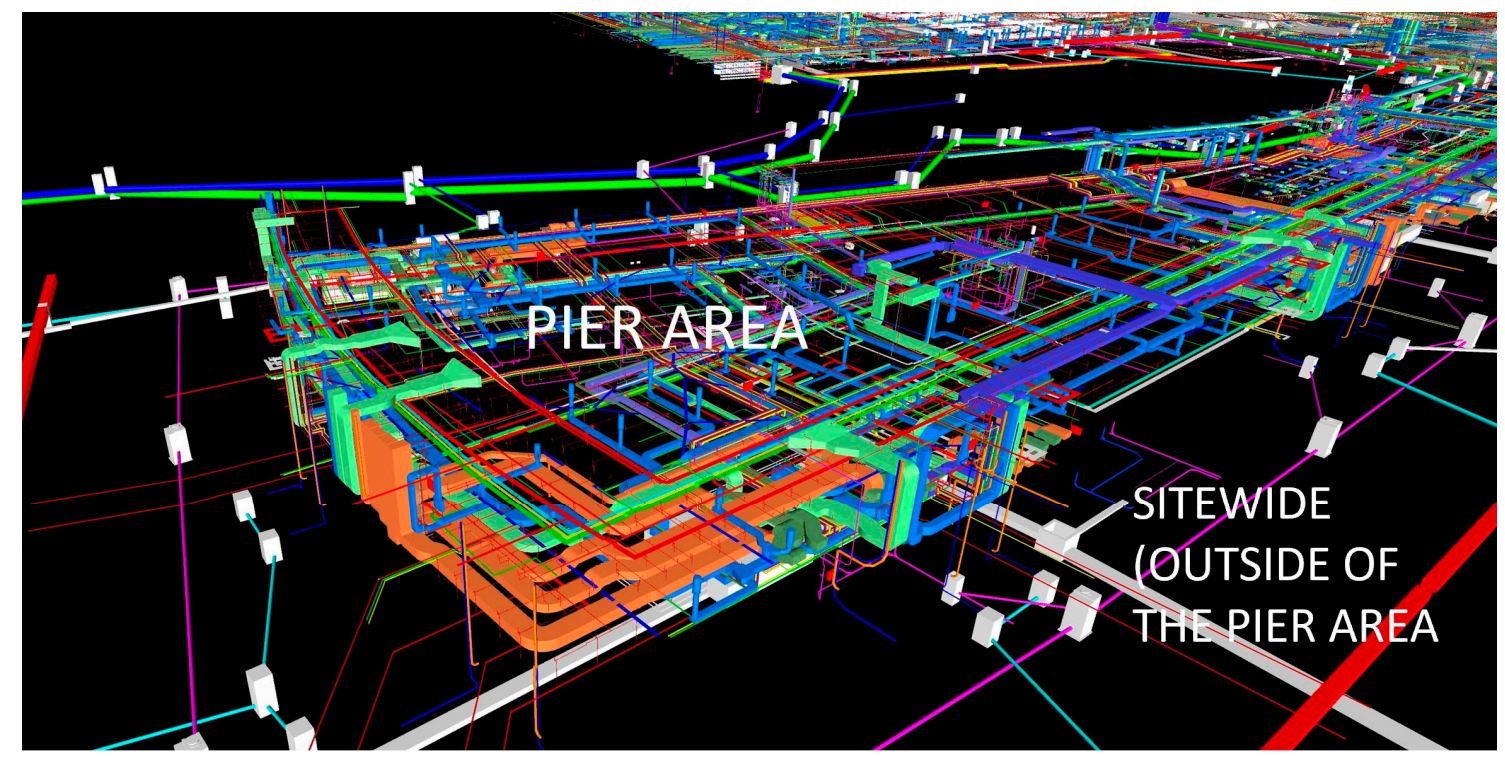

Figure 3. Viewpoint of the Merged MEP-Infrastructure INA BIM Model Focusing on a Pier Building Area. Blue \& Green \& Orange: HVAC Ducts, Purple: Waste water discharge line, Red pipes (inside the terminal area): Fire protection, Red (outside the terminal area): Underground network line composed of pipes, manholes, and slot drains, Red trays: Cable trays, Green \& Dark Blue (outside the terminal area): Landside drainage, White: Electrical duct banks with manholes. 


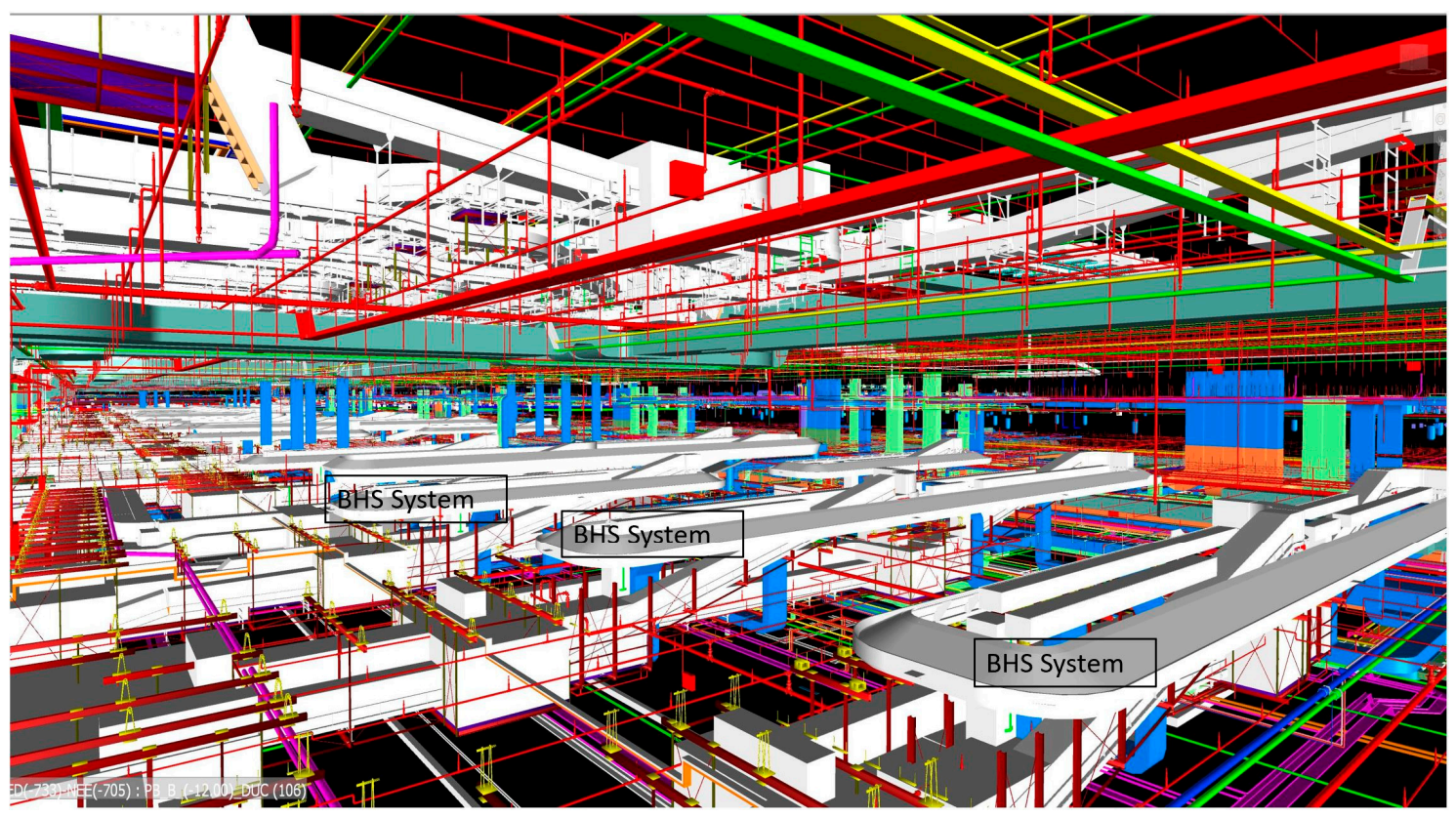

Figure 4. Viewpoint of the cross-coordination of the BHS systems and MEP elements within the Terminal Building Zone. Blue \& Green \& Orange Ducts: HVAC Ducts, Purple: Waste water discharge line, Red pipes (inside the terminal area): Fire protection, Red trays: Cable trays, Green trays: Low voltage cable trays, Yellow trays: Ultra low voltage cable trays.

The coordinated BIM model is obliged to be the only source used by the subcontractors to produce their shop drawings that are to be used on the site. However, because MEP subcontractors had limited experience in making interdependent disciplinary decisions on an integrative virtual platform for such a large-scale project, the coordination period included many conflicting iterative processes that needed to be defined and managed properly. As such, regulating and engineering MEP-IT subcontractors' 2D shop drawing production processes is reported as another major challenge, since the incompatible drawings with the coordinated BIM model are not accepted.

Moreover, even though the interoperability has not been a problem, since the file types for BIM deliverables are pre-determined as exchangeable formats in the INA BIM Execution Plan, managing cross-coordination on the airside region brings notable challenges in terms of following a different coordination schedule and extending a comparatively larger area requiring coordination between underground utilities, on-the-surface utilities (Figure 5), and surface models (e.g., runways), as listed in Table 1.

Achieving cultural change in complex projects is a process full of struggles. The incompatibility of the site work with the BIM model is one of the most crucial problems, because it has been known that the issues detected in relation to discrepancies between the coordinated BIM model and already manufactured zones on the sites have the potential to cause future coordination problems, waste and cost over-runs. Accordingly, it is also assessed that monitoring and controlling work on the site is one of the major challenges from a technical perspective. As far as the size and complexity of the project is concerned, managing all project individuals, mainly the subcontractors, becomes a very challenging issue that requires a comprehensive management plan [44]. In the very beginning of the project, a lack of awareness and experience of subcontractors and their resilient attitudes against engaging with BIM processes in their daily site and office work triggered the necessity for BIM training for all subcontractors through facilitated workshops. Not only the INA project case, but also the LHR T5 Project and DEN expansion project cases bear similarities in terms of an unsupportive organizational culture that was brought on by various project parties who had no or little experience with BIM technology and processes. It is stated that all parties brought their own practices that conflicted with the policies regarding $3 \mathrm{D}$ CAD uses, creating the greatest challenge in terms of getting people to 
actually implement 3D CAD as it is standardized by the owner [28]. Another study articulates another challenge of physical space constraint preventing co-location, and consequently preventing the full integration of the information flow during the design and construction [66]. Similarly, DEN mostly tackled the problem of reaching a consensus on collaboration in the BIM environment [70].

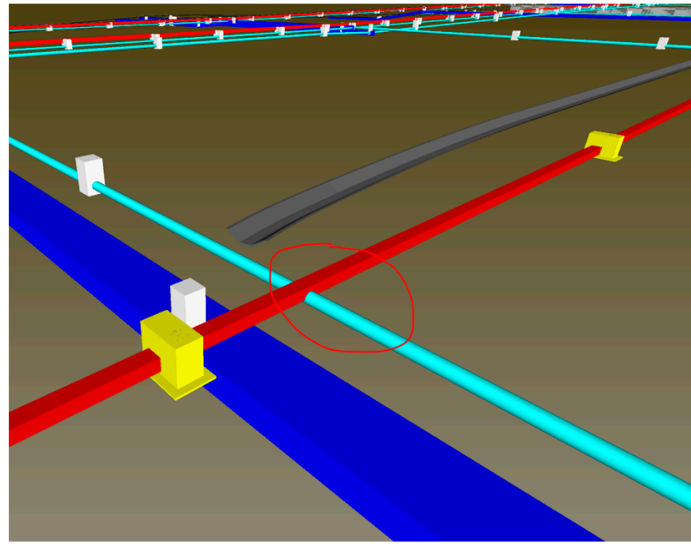

(a)

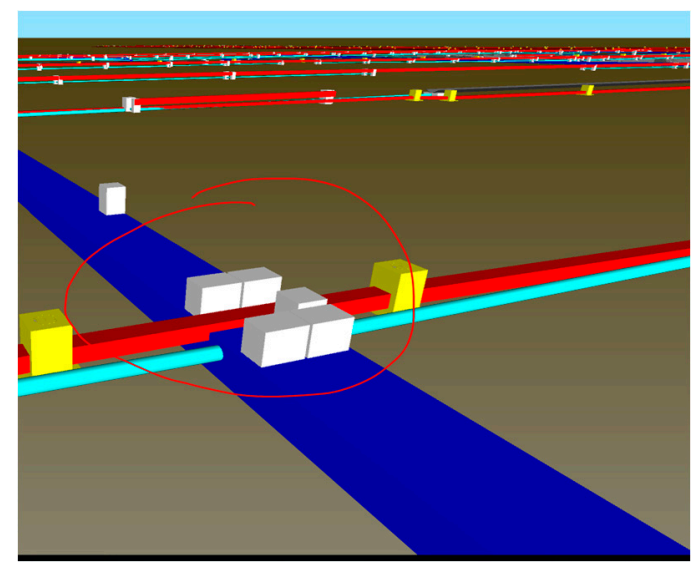

(b)

Figure 5. Clashes between the AGL, pipe and culvert models. (a) Clash between the AGL and pipe models; (b) Clash between the AGL and culvert models. Red: AGL, Cyan: Pipe, Dark Blue: Culvert.

Lastly, another challenge is extending the use of BIM to airport operations to create continuity in digital transformation. This is achievable through preparing asset registers in the BIM environment, but it requires a significant workload since the asset information development efforts have not started earlier with the involvement of designers. This can also be related to the challenge of a lack of awareness from the very beginning of the project. The INA BIM team reported that they had to check over 12,000 approved shop drawings, issued for construction (IFC) documents, and material approval forms (MAFs) to verify the ones that were needed for the systems classification and for commissioning the data creation. Similarly, because DEN was not sure what information they needed due to a lack of specifics in their requirements, they had to undergo a long path in reconciliation process for identifying and capturing the assets they needed for commissioning [31].

\subsection{Strategic Perspective}

Mega airports are very complex infrastructures, and can even be considered to be far more complex than any other infrastructure construction projects. They constitute a massive construction type utilizing large scale technologies and integrating complex ecosystems. The best way of managing mega airport projects is to have a solid grasp of how the whole system works together from the very beginning as a client-representative centralizing the project information in a virtual environment. This task has become more challenging as airports' key design and construction features have changed drastically in the last era. Design, engineering and construction have been handled concurrently, and procurement methods have been significantly changed. Additionally, new technologies have become crucial necessities to be followed closely, and have been applied to keep up with the digital-driven competition in the industry. The technology (e.g., BIM) itself has become the driver for diffusing other digital technologies and practices, and for challenging the industry [26]. As it is getting harder to maintain the competitive edge with digitization, with the abrupt advancement in ICT, the reason behind the competitiveness is not related to how spacious and mega the structure is, but it is related to the utilization of an integrated way of delivery procurement strategies to align stakeholders' interests and motivations. However, it is not easy to satisfy that alignment in the case of a highly fragmented construction industry. For instance, the Heathrow T5 Project faced the challenge of different project 
managers bringing different management styles and approaches to the project in the space of four years [71]. Hence, delivering the project as one team by bringing different stakeholders' practices on one virtual platform is the fundamental challenge to be targeted. It is observed that despite the contextual differences in managerial problems raised by the stakeholders regarding the BIM use within their practices, their reactions in terms of showing resistance remain the same. Another related challenge is making digital the driver for all parties. However, because the industry is more focused on the end-product rather than the process, the scoping phase should be defined more strategically.

Furthermore, managing and standardizing the BIM implementation on behalf of the client is a critical responsibility as there are underlying risks to be realized and mitigated by using the power of the digital. Having extensive technical knowledge and internalizing the requirements are important in addressing the issues on the subcontractors' side, such as claims. However, change management is perceived more as struggling in terms of social aspects and human behavior than technical issues are. This is realizable via comparing the timeline dedicated to the BIM technology platform establishment and the scoping. It took 3-4 months to implement the BIM platform with its full functionalities, whereas it took 30 months to scope and diffuse the BIM strategy.

In the future, we expect that there will be a smaller number of resources with more intelligent operations. The design-engineering-construction ecosystem will eventually be transferred to another ecosystem, which is operations. To satisfy the seamless data handover, an available digital environment should be efficient enough to reflect the operational environment requirements. If the vision of the BIM implementation strategy in the design, engineering and construction phases does not address the operational phase, then it is hard to justify the project success with a digital transformation in terms of the KPIs.

\subsection{Enablers}

The enablers of the BIM-enabled digital transformation in the INA project are assessed and consolidated via having two-phased semi-structured interviews, observations and reviews of the BIM documents. Likewise, challenges and enablers are also reported from a technical and strategic perspective, respectively. Based on the case analysis findings, a collaborative working environment, advanced project monitoring and control, BIM tools, BIM policy, and an organizational structure are the enablers that are used to overcome the aforementioned challenges.

\subsubsection{Technical Perspective}

To overcome the challenges encountered throughout the implementation of the BIM in this mega airport project, there are certain control mechanisms used at a technical level. These mechanisms were determined in the scoping phase of the BIM delivery to achieve a full integration of the project parties into the BIM environment.

It is essential to demonstrate how the design of different disciplines is delivered with BIM, and how the BIM model is taken over to the subcontractors to lead their work on-site. The BIM department which is represented by the INA BIM Management Team in Figure 6 is at the focal point of the BIM delivery landscape as being responsible for the managing, integrating, utilizing, and the monitoring and controlling of the BIM model data by creating a collaborative virtual work environment for all major stakeholders, including the designer, subcontractors, BIM modelers, and quality assurance and quality control (QA/QC) team. BIM models are generated at different levels of details, and the BIM data is utilized by generating clash reports; $4 \mathrm{D}$ scheduling; performance dashboards to have an effective control mechanism on the subcontractors' work on-site. Weekly BIM workshops, as well as BIM coordination meetings, are used as communication tools to oblige subcontractors to use BIM tools. BIM tools that are used to provide a cloud-based virtual collaborative platform for BIM integration are presented in Figure 7. The use of this BIM software enables the INA Project individuals to have a controlled work sharing, BIM coordination, design review, change visualization, quality management, and issue management, access to RFIs and submittals, and the notification of inspection documents. 
The BIM policy of the company declares strict contractual obligations for all subcontractors to make them follow and utilize the BIM process into their work processes, by for instance using mobile tablets on-site to fill out Notification for Inspection (NFI) documents to get their progress payment [44]. NFIs have become one of the major monitoring and control tools on-site for the client since issues regarding each manufactured zone are systematically detected zone-wise and asset-wise by INA BIM Site Engineers. The issues are created and managed on the Autodesk BIM 360 Field system periodically to track each subcontractor's performance on site. These reports are internally shared on a weekly basis. Accordingly, project parties who consist of the designers and subcontractors are familiarized with the use of the BIM tools as part of their daily work. For instance, there are 150 mobile tablets used on the site to assist site engineers in their construction work by providing all coordinated BIM models zone-wise. Apart from 3D models, approved 2D shop drawings are also provided for the field via mobile tablets.

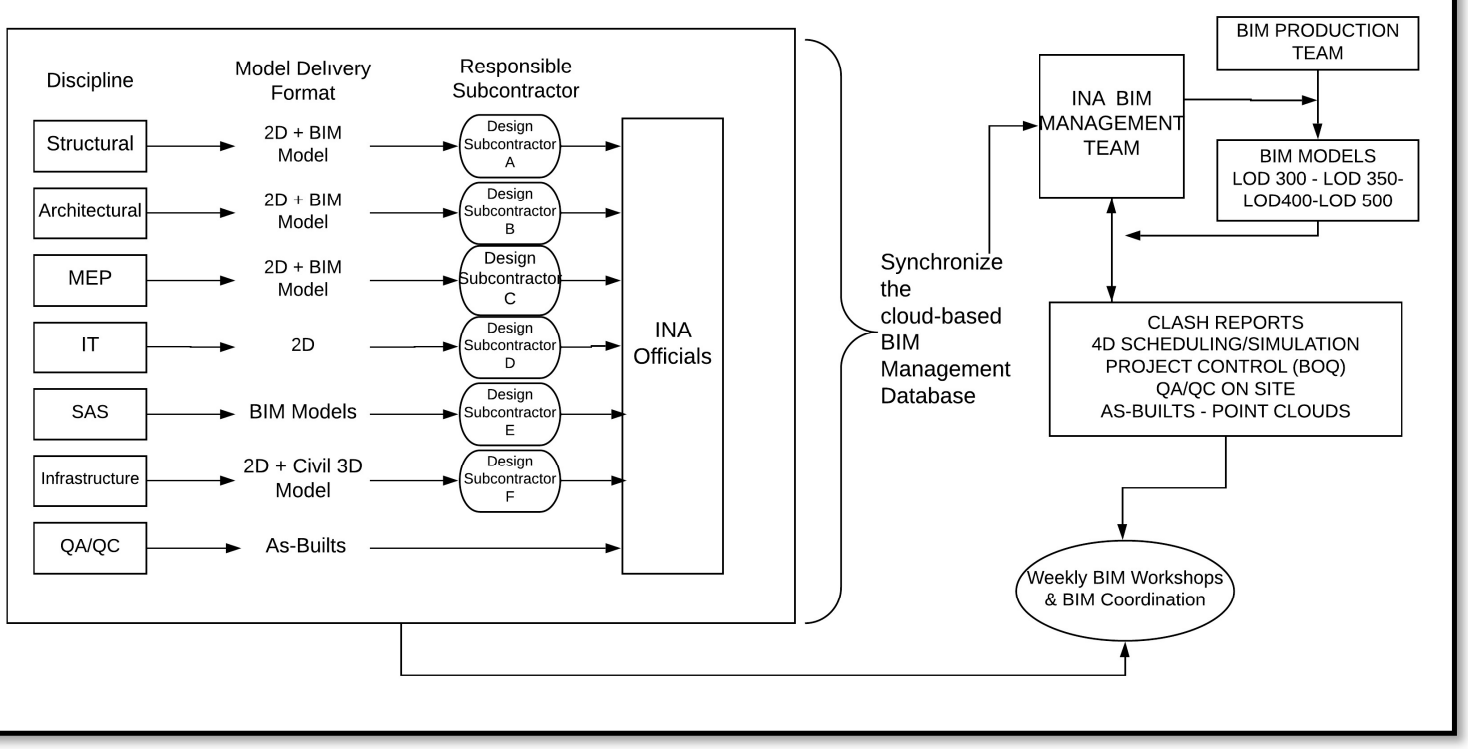

Figure 6. INA BIM Workflow (LOD: Level of Detail).

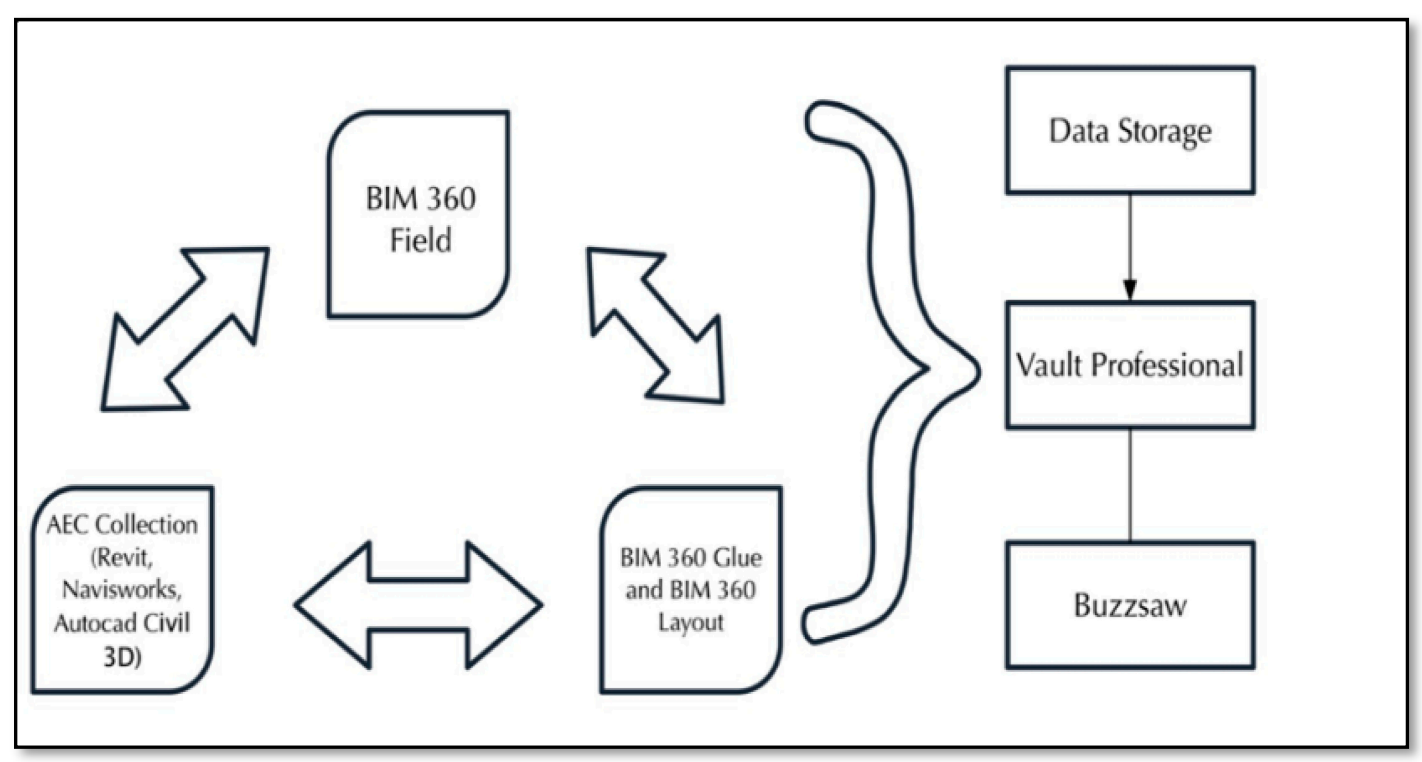

Figure 7. INA BIM Tools. 
Cloud- based digital documentation is a significant enabler, and the related applications, such as issue creation, model synchronization, and document approvals, take place on the Autodesk 360 Field platform. Additionally, a 4D model, including 30,000 activities, has been generated to track the progress on a daily and monthly basis, to have dynamic control over the progress of the project (See Figure 8). It is a collaborative effort amongst the INA officials, who do not only include the INA BIM Management Team. Baselines schedules in csv file formats prepared by each department are integrated in Navisworks via linking the schedule activities with the related model components. The simulation helps decision-makers in the project take preventive and/or corrective actions.

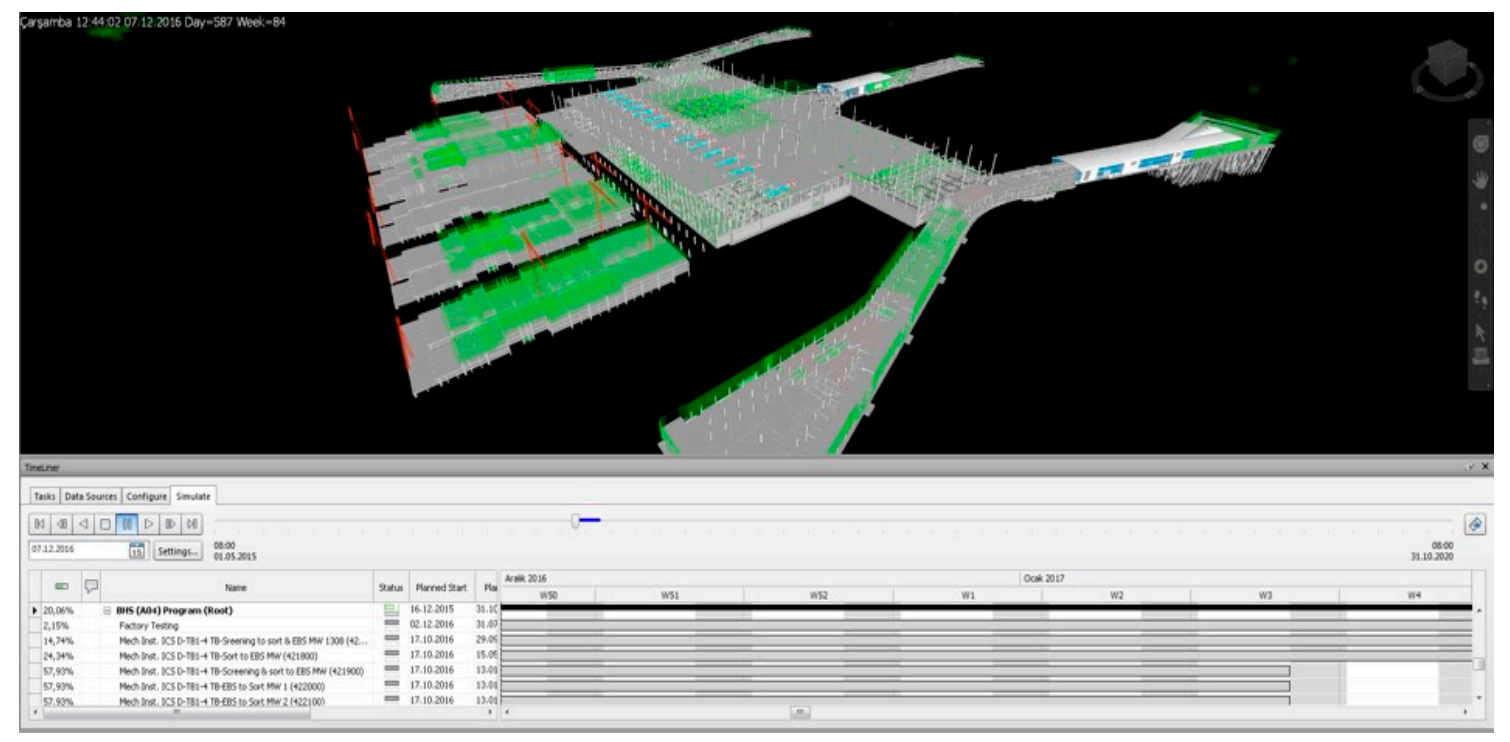

\begin{tabular}{|c|c|c|c|c|c|c|}
\hline \multicolumn{7}{|c|}{ INA_PB1_D_BEAMS CONCRETE } \\
\hline Reference Level & Family & \begin{tabular}{|c|} 
Type \\
\end{tabular} & Length & B & $\mathrm{H}$ & Volume \\
\hline PB_D_( \pm 0.00$)$ & Concrete-Rectangular Beam & INA_STRC_CBM_4PB06_200x2900 & 2440 & 200 & 2900 & $1.02 \mathrm{~m}^{3}$ \\
\hline $\mathrm{PB} D( \pm 0.00)$ & Concrete-Rectangular Beam & INA STRC CBM 4 PBO6 $200 \times 2900$ & 500 & 200 & 2900 & $0.24 \mathrm{~m}^{3}$ \\
\hline PB_D_ $( \pm 0.00)$ & Concrete-Rectangular Beam & INA_STRC_CBM_4PB06_200×2900 & 3054,348 & 200 & 2900 & $1.30 \mathrm{~m}^{3}$ \\
\hline PB_D_( $( \pm 0.00)$ & Concrete-Rectangular Beam & INA_STRC_CBM_4PB06_200x2900 & 5500 & 200 & 2900 & $2.16 \mathrm{~m}^{3}$ \\
\hline $\mathrm{PB} D( \pm 0,00)$ & Concrete-Rectangular Beam & INA STRC CBM 4 PBO6 $200 \times 2900$ & 15205,03 & 200 & 2900 & $6.21 \mathrm{~m}^{3}$ \\
\hline PB_D_ $( \pm 0.00)$ & Concrete-Rectangular Beam & INA_STRC_CBM_4PB06_200×2900 & 2354,348 & 200 & 2900 & $0.94 \mathrm{~m}^{3}$ \\
\hline PB_D_( \pm 0.00$)$ & Concrete-Rectangular Beam & INA_STRC_CBM_4PB06_200×2900 & 400 & 200 & 2900 & $0.24 \mathrm{~m}^{3}$ \\
\hline PB D $( \pm 0,00)$ & Concrete-Rectangular Beam & INA STRC CBM 4PBO6 200×2900 & 2354,348 & 200 & 2900 & $0.94 \mathrm{~m}^{3}$ \\
\hline
\end{tabular}

Figure 8. 4D Simulation view of the architectural and structural master BIM model.

Discipline-wise and zone-wise, clash detection is utilized throughout the design and construction phases. The frequency of generating clash detection reports depends upon the frequency of the design revisions. The periodicity of the clash detection is determined by the submission schedule of the subcontractors. However, the BIM department determines and controls the coordination process of the mechanical, electrical, plumbing and information technologies (MEP-IT) systems with a separate coordination workflow, as they require more of a coordination effort due to their highly complex nature within such a mega airport context (Figure 9). The workflow depicts the concurrent engineering and design in a fast track fashion, as well as the responsible parties in this process. The main objective is to resolve the clashes at the LOD 350 BIM level with the MEP designers and proceed to the extraction of the shop drawings out of the clash-free BIM model to push the work on the site [44]. The BIM models are continuously developed by the addition of various details, such as equipment details and specifications throughout the workflow. Every update of the BIM models and shop-drawings are shared on the cloud and made accessible via mobile tablets on the site.

Heathrow and DEN also followed similar approaches to overcome the major challenges they had in their BIM implementation processes. "Central to the delivery of T5 has been the concept of 
integrated teams" [71] indicates the enabler of the collaborative working environment. On the other hand, the BIM policy can be seen as the major enabler for DEN to be proactive in their BIM process, since the project team stated "We tried to predict the obvious issues and create a number of workflows to help solve those problems before they arose" [70].

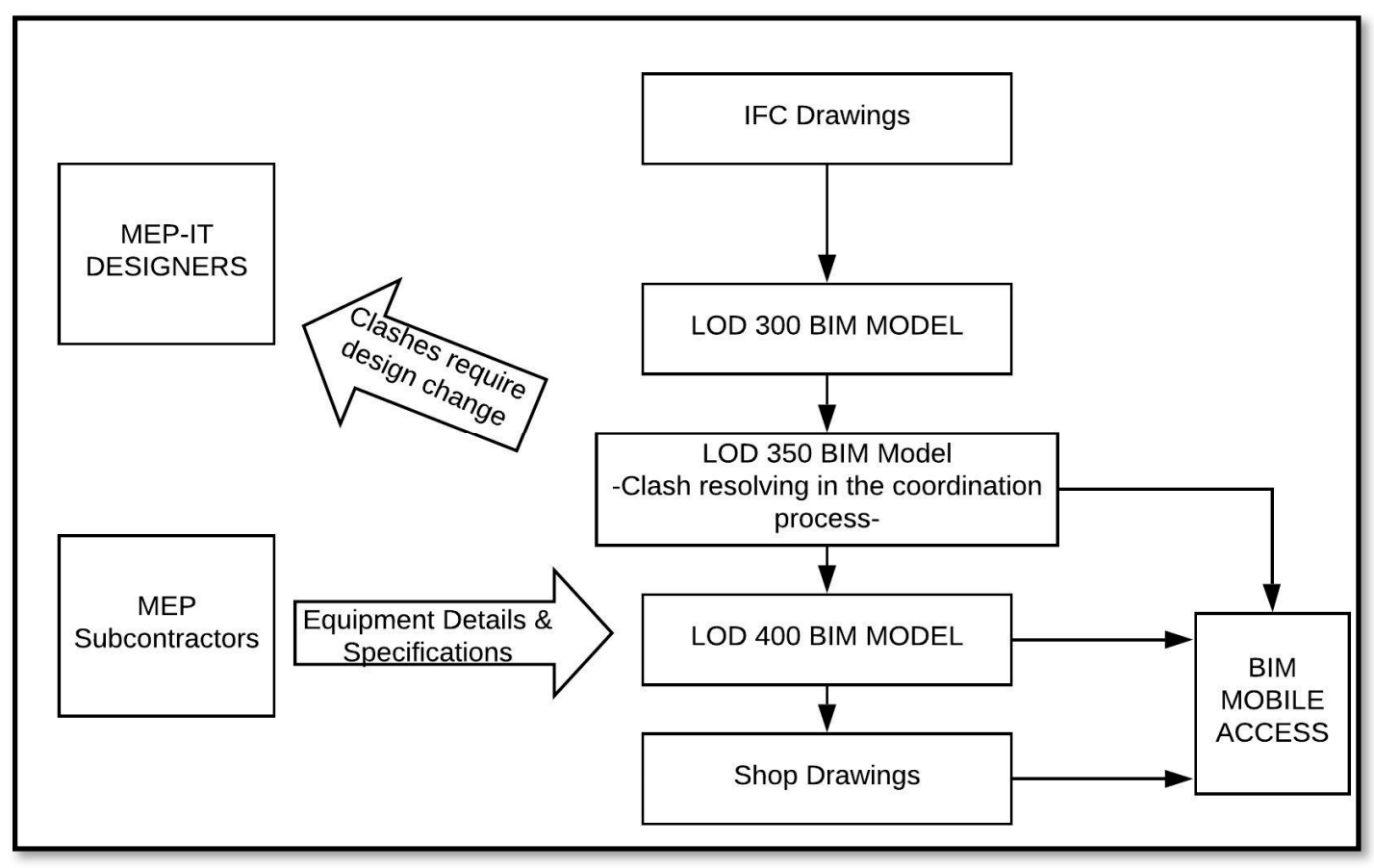

Figure 9. MEP-IT Coordination Workflow.

\subsubsection{Strategic Perspective}

In the case of the INA project, utilizing a strategy to follow an end-to-end fully digitized approach with a client representative mindset unfolds the key enabler for tackling the challenges. Airport Building Information Modeling (ABIM) implementation is the approach that enabled delivering the whole project lifecycle on behalf of the client. That being said, an integrated project delivery (IPD) mindset leading to a fully seamless delivery with a client-representative role is achieved through a digital platform which is the BIM platform.

Beyond the execution, within the start-to-end BIM delivery, which is a long journey of seamless execution, requirements are very well-defined and internalized by the BIM team on behalf of the client. All of the project teams deliver the project as one team by utilizing a seamless digital platform. One of the key enablers behind achieving this is the shortening of the BIM learning curves of the stakeholders by positioning a quick-learner young generation in facilitated workshops. Gil et al. [42] approaches the issue from a higher-level perspective and states that large capital projects like Heathrow T5 provide the opportunity of innovating large socio-technical systems. The key success driver is strategizing how you translate this complicated engineering process into the construction setting. Furthermore, BIM provides transparency, which can be considered as the power of the digital, and it provides confidence for the parties who closely follow and internalize the BIM processes.

Specific on-site mechanisms are also critical. Mobile BIM is one the backbones that facilitated the on-site manufacturing and coordination. Mobile BIM was the initial strategy from the beginning, but once the design \& engineering digital ecosystem needed to be translated into the construction site, it became a service toolkit that pushed the site team to leverage mobile BIM functionalities on the site. For each functionality, a workflow is developed. This workflow generation process needs a decent background and thought process to provide functionalities for step-by-step use. The use of mobile tablets enabled significant time savings by enhancing communication between the office and the site. 
One of the DEN Hotel and Transit Project representatives explains the process by "looking right at the install and seeing if it matches the model, and doing that within minutes" [68]. Additionally, the design for the manufacturing and assembly is also one of the key concepts followed throughout the project delivery to enable efficiency on the site.

Furthermore, the CTO at the time of the project demonstrates the enabler behind the required transformation as being the quick realization on the return of investment through the utilization of connected BIM from the construction to the operation with the right skillset and with the people transformation. Likewise, for the INA Project, DEN officials stated that The Federal General Services Administration identified the use of BIM as a best practice having significant abilities to diagnose problems and plan repairs, and they realized both the efficiencies and cost savings during the design and construction phases [69].

Grasping BIM as a transformative innovation process is significant in this journey. The Integrated Project Delivery mindset is at the center of the BIM implementation journey. In essence, the journey starts with the design, which includes the steps of conceptualizing, criteria design, and detailed design, followed by the delivery of the project with a comprehensive BIM execution plan, workflows, information flows, and right resource allocations. As the project is delivered, continuous assessment through an integrated project control and performance control are also conducted. Eventually, it is aimed to have a transformative impact, which leads to an increase in the productivity, efficiency and constructability of the project. This strategic approach of simultaneous digital innovation diffusion and transformation is depicted in Figure 10.

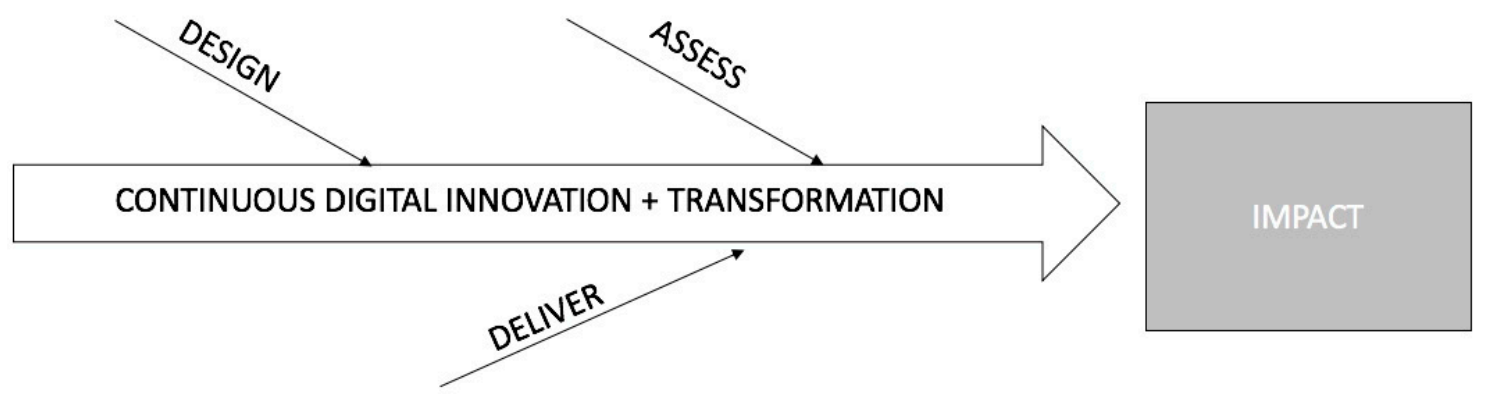

Figure 10. INA-BIM Management Strategy.

Overall, the AEC industry has been trying to achieve transformation in design, engineering and construction for over 10 years, and the same learning curve will also apply for digitization in operations. It can be stated that artificial intelligence, big data analytics, and more automated workflows will be key enablers for facilitating the BIM-enabled digital transformation in the life cycles of mega projects.

\section{Discussion}

The research findings concede a certain similarity with the major challenges and enablers reported in the literature. As described in Table 5 , the project complexity $[45,50,54]$, lack of experienced BIM professionals [48-50], lack of awareness [51,52] and unsupportive organizational culture [28,47,48] are valid for the INA case. While these challenges are encountered at both technical and executive levels, they are perceived differently. From a technical perspective, subcontractors' BIM incompetency has been exacerbated with design/engineering challenges due to the scale and complexity of the project. Additionally, the first BIM experiences in such a large-scale project have increased the level of unsupportive organizational culture reflected in the INA BIM team. The lack of awareness and unsupportive organizational culture are perceived from the strategic perspective that views how the priorities and interests of different parties show a wide variation and are often conflicted. On the other hand, the filtered challenges of a lack of financial resources [18,30], lack of governmental support [51,53], and lack of clear benefits $[31,45,46]$, are not observed in the INA case. Those potential challenges are absorbed by the project delivery model of public private partnership (P3). Following the proposed 
definition of P3-a long-term contractual agreement between public and private sectors where the private sector takes the responsibility of managing and operating the project by taking certain financial risks-by Garvin \& Bosso [72], the private sector brings its experience, best practices, and private capital to execute the required project with the support of the government. Thus, BIM awareness and experience at the executive level defies the challenge of a lack of clear benefits. Furthermore, government support facilitates the capital raising for the private sector as they can easily provide the upfront investment required for initiating BIM implementation.

Apart from the reported challenges, the INA BIM team has been faced with significant conflicts between both upstream and downstream project personnel because of the strict BIM deliverables. As the central BIM source, the INA BIM management team has had to manage the issues raised among the entire engineering and design ecosystem at the same time. This situation has also brought the challenge of risk management on behalf of the client. Overall, updating the control mechanisms as part of the BIM strategy have been required to sustain the BIM adoption rate.

Similar to the challenges, the enablers are also described along with the related literature (see Table 6). A collaborative working environment [12,24,55-59], advanced project monitoring and control system [34,35,57,59,60], BIM tools [12,18,23,61], BIM Policy [26,32,55,61-63], and organizational structure [64-66], are found to be key enablers for the INA BIM implementation case. Significant efforts, both at the technical and strategic levels, were made for maintaining the effectiveness of those enablers to overcome the perceived challenges. Accordingly, applying and overseeing the BIM strategies (e.g., workflows and workshops) are daily responsibilities of all BIM team members. Understanding and leveraging the interdependencies between the enablers is also key for the INA BIM team to diffuse the BIM implementation on such a large scale. The BIM policy, including the INA BIM execution plan and 30-month BIM strategy, was prepared according to the functionalities of the designated BIM tools. Additionally, supporting the use of open standards for BIM $[32,56]$ serves as an enabler bidirectionally. Not only for the INA BIM team, but also for the subcontractors, making IFC model exchanges available has provided flexibilities in certain cases to solve interoperability issues between different BIM tools used in the project. Consequently, ensuring that the right geometric and semantic data is exchanged without limiting project participants' choices of BIM tools is crucial in the INA project.

Moreover, the BIM team, comprised of a young generation, is aware of the importance of a solid BIM technology background in order to rapidly adjust to the changes in technology, and in order to solve unforeseen technical problems. Hence, this has become another key enabler that has led to concurrent learning and delivery as well as to continuity in digital transformation.

Lastly, the aforementioned projects of the LHR T5 and DEN Hotel and Transit Center Program possess certain similarities, and the reviewed challenges and enablers associated with these projects show a significant alignment with the ones analyzed in the INA case. In terms of the budget and project size, INA is the largest project in terms of being a new mega airport project. The differences in the project delivery methods and scopes impact the types of challenges and enablers on a technical level, and lead to unique approaches, even though the tools that are used remain the same. However, at the strategic level, the challenges-especially the ones in the social and cultural context-show a significant similarity in terms of the resistance against adopting more sophisticated tools and processes despite the differences in geographies, project times, and project duration. For example, when T5 was under construction, BIM was referred to as a 3D CAD technology, and the tools had restricted capacities, but at the time, when DEN and INA were constructed, BIM technologies (e.g., mobile BIM) were presented to a greater extent. It can be stated that, throughout time, human behavior shows consistency in its attitude against digital transformation through innovation.

\section{Conclusions}

The implementation of BIM in airport projects significantly varies from the typical applications of BIM to new building constructions in which the focus is on the design and construction of a sole building. Due to the siloed nature of airport projects, it is important to realize the dynamic relationships between 
key people, the technology, and processes, to understand how to provide digital transformation within an airport project context. The BIM implementation is a robust approach for merging the silos, and for speeding up the project delivery. The required integration of the silos through BIM should be first internalized, and then pushed at the executive level. Barriers evolve at an increasing rate throughout the project delivery of a mega project as new innovative and transformative approaches are introduced, but the core strategy should be maintained by decision-makers. Accordingly, the incentivizing of project parties through fast realizable project success outcomes via the efficient use of technology and via effective communication is key for the BIM implementation adoption. Since project parties can have varying competencies in BIM, having a pre-determined strategy to align their learning curves is important. Similarly, addressing the project KPIs with the use of digital technologies like BIM is also essential.

One of the BIM objectives in the INA project is to increase the productivity on the site to meet the schedule requirements. The competitive project duration for the first phase of the project is met because BIM-enabled digitalization serves as a catalyst for the concurrent engineering and design through the BIM implementation. Furthermore, INA has the largest scope and complexity with the shortest project duration, when compared to the expansion projects of LHR and DEN. This unveils the scale of efficiency provided by digital transformation in such a mega project.

The impacts of BIM-enabled digital transformation can be assessed at the project, firm, and industry levels [42]. It is shown that that BIM-as construction innovation-brings benefits at all levels through the in-depth analysis of the INA case study. The design and construction phases of the first phase of the INA project has been completed on time and on budget, as they have been fully transformed around the digital. The interviews, observations, and analysis of documentations show that even though introducing cultural change is difficult to achieve, the motivation generated by the digital power for project team members to integrate their work on the BIM platform overcomes the barriers.

Compared to other project types, strategizing BIM implementation for airports is highly challenging due to the engineering and business complexity of the encapsulated infrastructure systems, which need significant foreseeing in the design, engineering and construction phases to address operational requirements. Additionally, because the success of BIM mainly depends on the effectiveness of the synergy created within the virtual collaborative environment, the highly siloed nature of the airport projects introduces a certain challenge in terms of the high number of interfaces and communication channels that might possibly show resistance within that environment. Accordingly, it is seen that the discussed challenges co-exist with a higher variation, so that they should be optimally tackled with enablers. Thus, as presented in this study, strategic and technical perspectives should be assessed together for such a mega-scale infrastructure project, given that their complementarity and alignment are essential for the success of the BIM implementation.

Through this study, a novel practice of a start-to-end BIM strategy, laying the foundation for its use for the operations of a mega-scale airport infrastructure project delivery, is presented through key components of a theoretical framework of innovation diffusion. Additionally, the paper offers a scalable approach to manage a complex engineering and business case by explaining the INA case from both managerial and technical perspectives. We justify that it is important to transform traditional processes so that every stakeholder can find a value in the digital, in order to successfully deliver a mega project.

Author Contributions: Conceptualization, O.K., B.K. and B.O.; Methodology, O.K., B.K. and B.O.; Validation, O.K., B.K. and B.O.; Formal analysis, B.K.; Investigation, B.K.; Resources, O.K.; Data Curation, B.K.; Writing—original draft preparation, O.K., B.K. and B.O.; Writing-review and editing, O.K., B.K. and B.O.; Visualization, B.K.; Supervision, O.K., B.O.; Project administration, O.K., B.K., B.O.

Funding: This research received no external funding.

Conflicts of Interest: The authors declare no conflict of interest. 


\section{References}

1. World Economic Forum; The Boston Consulting Group. Shaping the Future of Construction: A Breakthrough in Mindset and Technology; World Economic Forum: Geneva, Switzerland, 2016. Available online: http://59.80.44. 44/www3.weforum.org/docs/WEF_Shaping_the_Future_of_Construction_full_report_.pdf (accessed on 25 April 2019).

2. Merrow, E.W.; McDonnell, L.; Arguden, R.Y. Understanding the Outcomes of Mega-Projects; The RAND Corporation: Santa Monica, CA, USA, 1988.

3. Sun, J.; Zhang, P. Owner organization design for mega industrial construction projects. Int. J. Proj. Manag. 2011, 29, 828-833. [CrossRef]

4. Ezzat Othman, A.A. Challenges of mega construction projects in developing countries. Organ. Technol. Manag. Constr. Int. J. 2017, 5, 730-746. [CrossRef]

5. Zhai, L.; Xin, Y.; Cheng, C. Understanding the Value of Project Management From a Stakeholder's Perspective: Case Study of Mega- Project Management. Proj. Manag. J. 2009, 40, 99-109. [CrossRef]

6. Abood, D.; Quilligan, A.; Narsalay, R. Industry X.0 Combine and Conquer: Unlocking the Power of Digital. Accenture, 2017. Available online: https://www.accenture.com/_acnmedia/Accenture/ConversionAssets/DotCom/Documents/Global/PDF/Dualpub_26/Accenture-Industry-XO-whitepaper.pdf (accessed on 25 April 2019).

7. Gartner Digital Business Transformation-Gartner IT Glossary. Available online: https://www.gartner.com/ it-glossary/digital-business-transformation/ (accessed on 18 March 2019).

8. World Economic Forum; The Boston Consulting Group. An Action Plan to Accelerate Building Information Modeling (BIM) Adoption; World Economic Forum: Geneva, Switzerland, 2018.

9. Ding, Z.; Liu, S.; Liao, L.; Zhang, L. A digital construction framework integrating building information modeling and reverse engineering technologies for renovation projects. Autom. Constr. 2019, 102, 45-58. [CrossRef]

10. Azhar, S. Building Information Modeling (BIM): Trends, Benefits, Risks, and Challenges for the AEC Industry. Leadersh. Manag. Eng. 2011, 11, 241-252. [CrossRef]

11. Transparency Market Research (TMR). Growing Construction Industry to Drive Global Building Information Modeling ( BIM ) Market to US \$ 11. 5 bn by 2022; Transparency Market Research: Albany, NY, USA, 2016.

12. Costin, A.; Adibfar, A.; Hu, H.; Chen, S.S. Building Information Modeling (BIM) for transportation infrastructure-Literature review, applications, challenges, and recommendations. Autom. Constr. 2018, 94, 257-281. [CrossRef]

13. Fortin, J.; Bloomfield, P.; Mahaz, J.; Alfaqih, L. Guidebook for Advanced Computerized Maintenance Management System Integration at Airports, 1st ed.; Lamberton, S., Ed.; National Academies Press: Washington, DC, USA, 2018; ISBN 978-0-309-44679-2.

14. Sherry, L. Introduction to Airports Design and Operations; George Mason University Center for Air Transportation Systems Research: Washington, DC, USA, 2009.

15. van Uffelen, C. Airport Architecture, 1st ed.; Rogers, L., Ed.; Braun Publishing: Berlin, Germany, 2012.

16. Keast, R.L.; Baker, D.C.; Brown, K. Balancing infrastructure for the airport metropolis. In Proceedings of the 2008 First International Conference on Infrastructure Systems and Services: Building Networks for a Brighter Future (INFRA), Rotterdam, The Netherlands, 10-12 November 2008.

17. Horonjeff, R.; McKelvey, F.; Sproule, W.J.; Young, S.B. Planning and Design of Airports, 5th ed.; McGraw-Hill: New York, NY, USA, 2010; ISBN 978-0-07-164255-2.

18. Eastman, C.; Teicholz, P.; Sacks, R.; Liston, K. BIM Handbook: A Guide to Building Information Modeling for Owners, Managers, Designers, Engineers and Contractors, 2nd ed.; Wiley: Hoboken, NJ, USA, 2011; ISBN 978-0-470-54137.

19. Porter, M.E.; Millar, V.E. Harvard Business Review; Harvard Business School Publishing: Boston, MA, USA, 1985.

20. Moore, J.F. Harvard Business Review; Harvard Business School Publishing: Boston, MA, USA, 1993.

21. Heppelmann, J.E.; Porter, M.E. Harvard Business Review; Harvard Business School Publishing: Boston, MA, USA, 2014.

22. Ustundag, A.; Cevikcan, E. Springer Series in Advanced Manufacturing Industry 4.0: Managing the Digital Transformation; Springer: Berlin/Heidelberg, Germany, 2018; ISBN 978-3-319-57869-9.

23. Aziz, N.D.; Nawawi, A.H.; Ariff, N.R.M. ICT Evolution in Facilities Management (FM): Building Information Modelling (BIM) as the Latest Technology. Procedia Soc. Behav. Sci. 2016, 234, 363-371. [CrossRef] 
24. Wu, W.; Mayo, G.; McCuen, T.L.; Issa, R.R.A.; Smith, D.K. Building Information Modeling Body of Knowledge. I: Background, Framework, and Initial Development. J. Constr. Eng. Manag. 2018, 144, 04018065. [CrossRef]

25. Oesterreich, T.D.; Teuteberg, F. Understanding the implications of digitisation and automation in the context of Industry 4.0: A triangulation approach and elements of a research agenda for the construction industry. Comput. Ind. 2016, 83, 121-139. [CrossRef]

26. Shibeika, A.; Harty, C. Diffusion of digital innovation in construction: A case study of a UK engineering firm. Constr. Manag. Econ. 2015, 33, 453-466. [CrossRef]

27. ECONOMYWATCH World Construction Industry. Available online: http://www.economywatch.com/worldindustries/construction/world.html (accessed on 18 March 2019).

28. Harty, C. Innovation in construction: A sociology of technology approach. Build. Res. Inf. 2005, 33, 512-522. [CrossRef]

29. Holzer, D. The BIM Manager's Handbook: Guiadance for Professionals in Architecture, Engineering, and Construction, 1st ed.; Wiley: West Sussex, UK, 2016; ISBN 978-1-118-98231-0.

30. Yang, E.; Hua, Y. Framework of Construction Innovation: A Review of Diffusion of Sustainable Innovation in the Building Sector; ACSE: Reston, VA, USA, 2014; pp. 2096-2105.

31. Jones, S.A.; Laquidara-Carr, D. The Business Value of BIM for Infrastructure 2017; Dodge Data \& Analytics: Bedford, MA, USA, 2017.

32. Bradley, A.; Li, H.; Lark, R.; Dunn, S. BIM for infrastructure: An overall review and constructor perspective. Autom. Constr. 2016, 71, 139-152. [CrossRef]

33. Jones, S.A.; Bernstein, H.M. The Business Value of BIM for Infrastructure: Addressing America's Infrastructure Challenges with Collaboration and Technology; McGraw-Hill Construction: Bedford, MA, USA, 2012.

34. Koseoglu, O.; Nurtan-Gunes, E.T. Mobile BIM implementation and lean interaction on construction site: A case study of a complex airport project. Eng. Constr. Archit. Manag. 2018, 25, 1298-1321. [CrossRef]

35. Koseoglu, O.; Sakin, M.; Arayici, Y. Exploring the BIM and lean synergies in the Istanbul Grand Airport construction project. Eng. Constr. Archit. Manag. 2018, 25, 1339-1354. [CrossRef]

36. Yin, R.K. Case Study Research Design and Methods, 2nd ed.; Yin, R.K., Ed.; Sage Publications: Thousand Oaks, CA, USA, 1994; ISBN 9780511803123.

37. Seale, C. Quality in qualitative research. Qual. Inq. 1999, 5, 465-478. [CrossRef]

38. Flyvbjerg, B. Five Misunderstandings About Case-Study Research. Qual. Inq. 2006, 12, 219-245. [CrossRef]

39. Kallio, H.; Pietilä, A.M.; Johnson, M.; Kangasniemi, M. Systematic methodological review: Developing a framework for a qualitative semi-structured interview guide. J. Adv. Nurs. 2016, 72, 2954-2965. [CrossRef]

40. Turner, S.F.; Cardinal, L.B.; Burton, R.M. Research Design for Mixed Methods: A Triangulation-based Framework and Roadmap. Organ. Res. Methods 2017, 20, 243-267. [CrossRef]

41. Scapens, R.W. Researching management accounting practice: The role of case study methods. Br. Account. Rev. 1990, 22, 259-281. [CrossRef]

42. Ozorhon, B. Analysis of Construction Innovation Process at Project Level. J. Manag. Eng. 2012, $29,455-463$. [CrossRef]

43. Krosnick, J.A.; Presser, S. Question and Questionnaire Design. In Handbook of Survey Research; Wright, J.D., Marsden, P.V., Eds.; Elsevier: San Diego, CA, USA, 2009; ISBN 978-1-84855-224-1.

44. Keskin, B.; Ozorhon, B.; Koseoglu, O. BIM Implementation in Mega Projects: Challenges and Enablers in the Istanbul Grand Airport (IGA) Project. In Advances in Informatics and Computing in Civil and Construction Engineering; Springer: Berlin/Heidelberg, Germany, 2018; pp. 881-888. ISBN 9783030002206.

45. Gil, N.; Miozzo, M.; Massini, S. The innovation potential of new infrastructure development: An empirical study of Heathrow airport's T5 project. Res. Policy 2012, 41, 452-466. [CrossRef]

46. Hurtado, K.; Sullivan, K. How to measure the benefits of BIM-A case study approach. Autom. Constr. 2012, 24, 149-159.

47. Redmond, A.; Hore, A.; Alshawi, M.; West, R. Exploring how information exchanges can be enhanced through Cloud BIM. Autom. Constr. 2012, 24, 175-183. [CrossRef]

48. Gerges, M.; Austin, S.; Mayouf, M.; Ahiakwo, O.; Jaeger, M.; Saad, A.; Gohary, T.-E. An investigation into the implementation of building information modelingin the middle east. J. Inf. Technol. Constr. 2017, 22, 1-15.

49. Bui, N.; Merschbrock, C.; Munkvold, B.E. A Review of Building Information Modelling for Construction in Developing Countries. Procedia Eng. 2016, 164, 487-494. [CrossRef] 
50. Doloi, H.; Varghese, K.; Raphael, B. Drivers and Impediments of Building Information Modelling from a Social Network Perspective. In Proceedings of the 32nd ISARC, Oulu, Finland, 15-18 June 2015; pp. 1-8.

51. Khosrowshahi, F.; Arayici, Y. Roadmap for implementation of BIM in the UK construction industry. Eng. Constr. Archit. Manag. 2016, 23, 751-764. [CrossRef]

52. Succar, B.; Sher, W.; Williams, A. Measuring BIM performance: Five metrics.pdf. Archit. Eng. Des. Manag. 2012, 8, 120-142. [CrossRef]

53. Li, H.; Wang, Y.; Yan, H.; Deng, Y. Barriers of BIM Application in China-Preliminary Research. In Proceedings of the ASCE ICCREM, Edmonton, AB, Canada, 29 September-1 October 2016; Volume 1986, pp. 1311-1317.

54. Senescu, R.R.; Aranda-Mena, G.; Haymaker, J.R. Relationships between Project Complexity and Communication. J. Manag. Eng. 2012, 29, 183-197. [CrossRef]

55. McCuen, T.L.; Pittenger, D.M. Building Information Modeling for Airports; The National Academies Press: Washington, DC, USA, 2016.

56. Lu, W.; Zhang, D.; Rowlinson, S. Bim Collaboration: A Conceptual Model and Its Characteristics; Association of Researchers in Construction Management: Edinburgh, UK, 2013; pp. 25-34.

57. Abdirad, H.; Pishdad-Bozorgi, P. Developing a Framework of Metrics to Assess Collaboration in Integrated Project Delivery. In Proceedings of the 50th Annual International Conference of the Associated Schools of Construction, Washington, DC, USA, 26-28 March 2014.

58. Guo, J.; Wang, X.; Kang, S.-C.; Luo, H.; Li, J.; Jiao, Y.; Wang, J.; Wang, Y. Benefits of Building Information Modelling in the Project Lifecycle: Construction Projects in Asia. Int. J. Adv. Robot. Syst. 2014, 11, 1-11.

59. Becerik-Gerber, B.; Ku, K.; Jazizadeh, F. BIM-Enabled Virtual and Collaborative Construction Engineering and Management. J. Prof. Issues Eng. Educ. Pract. 2012, 138, 234-245. [CrossRef]

60. Abdirad, H.; Pishdad-Bozorgi, P. Trends of Assessing BIM Implementation in Construction Research. In Proceedings of the Computing in Civil and Building Engineering, Orlando, FL, USA, 23-25 June 2014; Issa, R.I., Ed.; pp. 496-503.

61. Succar, B. Building information modelling framework: A research and delivery foundation for industry stakeholders. Autom. Constr. 2009, 18, 357-375. [CrossRef]

62. Patacas, J.; Dawood, N.; Vukovic, V.; Kassem, M. BIM for facilities management: Evaluating BIM standards in asset register creation and service life. J. Inf. Technol. Constr. 2015, 20, 313-331.

63. Ma, X.; Xiong, F.; Olawumi, T.O.; Dong, N.; Chan, A.P.C. Conceptual Framework and Roadmap Approach for Integrating BIM into Lifecycle Project Management. J. Manag. Eng. 2018, 34, 05018011. [CrossRef]

64. Riitta, S.; Hirvensalo, A. Implementation of Building Information Modeling (BIM)—A Process Perspective. In Proceedings of the APMS 2008 Innovations in Networks Implementation; Smeds, R., Ed.; Springer: Helsinki, Finland, 2008; pp. 379-386.

65. Al Ahbabi, M.; Alshawi, M. BIM for client organisations: A continuous improvement approach. Constr. Innov. 2015, 15, 402-408. [CrossRef]

66. Badi, S.; Diamantidou, D. A social network perspective of building information modelling in Greek construction projects. Archit. Eng. Des. Manag. 2017, 13, 406-422. [CrossRef]

67. Evans, C.; Lewis, J. Analysing Semi-Structured Interviews Using Thematic Analysis: Exploring Voluntary Civic Participation Among Adults; SAGE: Thousand Oaks, CA, USA, 2017; ISBN 9781526439284.

68. Carter, N.; Bryant-Lukosius, D.; Blythe, J.; Neville, A.J.; DiCenso, A. The Use of Triangulation in Qualitative Research. Oncol. Nurs. Forum 2014, 41, 545-547. [CrossRef] [PubMed]

69. Mortenson DIA Hotel and Transit Center. Available online: https://www.mortenson.com/denver/projects/ dia-hotel-and-transit-center (accessed on 28 March 2019).

70. Ball, B.Y.M. Denver's Airport Expansion Primes a Push Toward BIM for Facility Management; Autodesk: San Rafael, CA, USA, 2013.

71. Brady, T.; Davies, A.; Gann, D.; Rush, H. Learning to manage mega projects: The case of BAA and Heathrow Terminal 5. Proj. Perspect. 2006, 29, 32-39.

72. Garvin, M.J.; Bosso, D. Assessing the Effectiveness of Infrastructure Public-Private Partnership Programs and Projects. Public Work Manag. Policy 2008, 13, 162-178. [CrossRef]

(C) 2019 by the authors. Licensee MDPI, Basel, Switzerland. This article is an open access article distributed under the terms and conditions of the Creative Commons Attribution (CC BY) license (http://creativecommons.org/licenses/by/4.0/). 